\title{
The dam-break problem for eroding viscoplastic fluids
}

\author{
B. M. Bates ${ }^{\mathrm{a}, 1}$, C. Ancey ${ }^{\mathrm{a}, 1}$, \\ ${ }^{a}$ Environmental Hydraulics Laboratory, École Polytechnique Fédérale de Lausanne, EPFL \\ ENAC IIC LHE, Btiment GC (Station 18), 1015 Lausanne, Switzerland
}

\begin{abstract}
Natural gravity-driven flows can increase in volume by eroding the bed on which they descend. This process is called basal entrainment and is thought to play a key role in the bulk dynamics of geophysical flows. Although its study is difficult using field measurements, basal entrainment is more easily amenable to analysis using laboratory experiments. We studied basal entrainment by conducting dam-break experiments releasing a fixed amount of viscoplastic fluid (a Herschel-Bulkley fluid) on a sloping, erodible bed of fixed depth. Entrainment was observed continuously, far from the sidewalls, using cameras. Bed material was quickly entrained, which led to flow advancement. Although the slope inclination had clear effects on the entrainment mechanisms, as shown by the internal measurements, this did not translate into faster front progression. Instead, the depth and length of the entrainable material were the most important controlling parameters of front velocity, as the surge scoured out the entrainable layer, pushing the entrainable material downstream and following the rigid bed's geometry. Bulk measurements (front position and flow depth profile) were also compared with predictions from lubrication theory.
\end{abstract}

Keywords: geophysical gravity-driven flows, basal entrainment, viscoplastic fluids, dam break, lubrication theory

Email address: christophe.ancey@epfl.ch (C. Ancey) 


\section{Introduction}

Gravity driven flows, such as snow avalanches and debris flows, pose a threat to human activities and settlements in mountain areas. The economic importance of these activities (e.g. mining, forestry, electricity production, tourism, transportation) has encouraged research into methods for calculating the main features of these flows (e.g. run-out distance, flow depth, impact force) [1]. In the 1960s, the idea emerged that an analogy could be made between avalanches and water flows, and since then the Saint-Venant equations have been increasingly used to describe the motion of "snow floods" [2-4], rock avalanches [5], debris flows [6], turbidity currents [7], and submarine avalanches [8].

Although the analogy with water waves has been pivotal to laying out the mass and momentum balance equations, there are crucial differences between water and natural materials involving mixtures of fluids and solids. A large amount of research has been done to determine the effects of bulk composition on rheological behaviour, flow resistance and self-organisation during flow. Another key difference between water and natural materials is related to mass exchanges between the flow and the bed: gravity driven flows can grow in size by mobilising loose material lying in their paths, or they can lose mass as a result of various processes (e.g. levee formation, debulking due to solid particle sedimentation) [9-15]. This raised the question of whether basal entrainment affects bulk dynamics. For instance, for powder-snow avalanches, Kulikovskiy and Svehnikova [16] developed a simple model which took into account the incorporation of air and snow and showed that basal entrainment plays an essential part in the growth of high-velocity avalanches. Without snow entrainment, air entrainment causes a dilution of the snow cloud, and thus a decrease in buoyancy forces [17]. Generalising the depth-averaged Saint-Venant equations to eroding flows mobilising natural materials has proved challenging to the different groups working on the issue. Recently, Iverson and Ouyang [18] reviewed the various attempts to model mass exchanges between flows and beds within the framework of the Saint-Venant equations. They showed that many existing models 
violated mass and momentum conservation laws, mostly because the boundary conditions at the bed-flow interface were incorrect. One underlying issue raised by their review was the absence of closure equations for the entrainment and deposition rates.

To shed light on basal entrainment's effects on the behaviour of gravitydriven flows, we investigate a problem that retains the essential features of natural scenarios, while being sufficiently simple to be manageable semi-analytically. We consider the dam-break problem for a viscoplastic fluid, i.e. the flow of a fixed volume of fluid suddenly released down a slope from a reservoir. The sloping bed is a solid substrate, but at a certain distance from the reservoir, the flow enters into contact with an erodible stationary layer composed of the same fluid and starts entraining it. We sought to determine how basal entrainment affected the front position and flow-depth profile over time.

The viscoplastic dam-break problem is a typical example of time-dependent flow, in which the flow passes through different phases from release to runout. This problem has been studied within the frameworks of the Saint-Venant equations [19-22] and lubrication theory [23-30]. Based on the assumptions that the flow is shallow (i.e. the aspect ratio $\epsilon=L / H$, where $L$ and $H$ denote scales of length and depth) and slow (i.e. the Reynolds flow number is low), lubrication theory approximates the local momentum-balance equation using an asymptotic expansion in $\epsilon$. The decisive advantage of lubrication theory over the Saint-Venant equations is that the velocity and stress fields are calculated with no recourse to closure equations as long as inertia plays a negligible role.

In the present paper, we focus on a nonlinear class of viscoplastic materials called Herschel-Bulkley fluids. Viscoplastic materials behave like fluids when they are sufficiently stressed, but like solids when the stress state is below a given threshold (called the yield stress) [31-34]. As natural materials exhibit solid- and fluid-like properties, the use of viscoplastic models has been proposed in order to describe the rheological behaviour of snow [35], mud [20], debris mixtures [36-38], lava [39] and submarine mud [8]. Actual rheological behaviour exhibits complex properties-such as two-phase effects (pore pres- 
sure diffusion), dilatancy, particle migration and segregation [6, 40-42] - which are not accounted for by the simple constitutive equations of single-phase continua such as the Herschel-Bulkley equation. Yet in spite of these limitations, the Herschel-Bulkley equation provides a useful approximation of various natural viscoplastic flows $[20,22,24,27,28,43-47]$. As viscoplastic models deal with the solid-liquid transition, they also seem relevant for describing basal entrainment: part of the bed may yield under the effects of the normal and shear stresses exerted by the flow, and then be entrained in that flow. This is, for instance, what is thought to happen in snow avalanches [48-50].

In this paper, we tackle the issue of basal entrainment using lubrication theory. We begin with a theoretical perspective of basal entrainment in shallow flows within the framework of lubrication theory (see Sec. 2). In Sec. 3, we describe the experimental procedure used for measuring the flow variables and observing what happens inside eroding flows. Section 4 presents our experimental results and compares them with theoretical predictions from lubrication theory. Section 5 concludes the paper. Three videos are available to accompany this paper (the acknowledgements section provides the link to the data repository).

\section{Dam-break wave eroding a stationary layer}

This section examines the effects of basal entrainment on the front motion of a viscoplastic avalanche. Let us consider that at time $t=0$, an avalanche made up of a Herschel-Bulkley fluid is released from a reservoir. Initially the fluid material flows over a sloping solid boundary. The bottom inclination is denoted by $\theta$. At time $t=t_{0}$, the material encounters a stationary layer made up of the same fluid and occupying a step of length $\ell_{\text {bed }}$ (see Fig. 1). The viscoplastic flow spreads across this stationary layer and entrains part of it. The front position is denoted by $x_{f}(t)$, the flow depth by $h(x, t)$ and the velocity field by $\boldsymbol{u}=(u, w)$. We use a Cartesian frame with the $x$-axis pointing downward and the $z$-axis normal to the slope. 


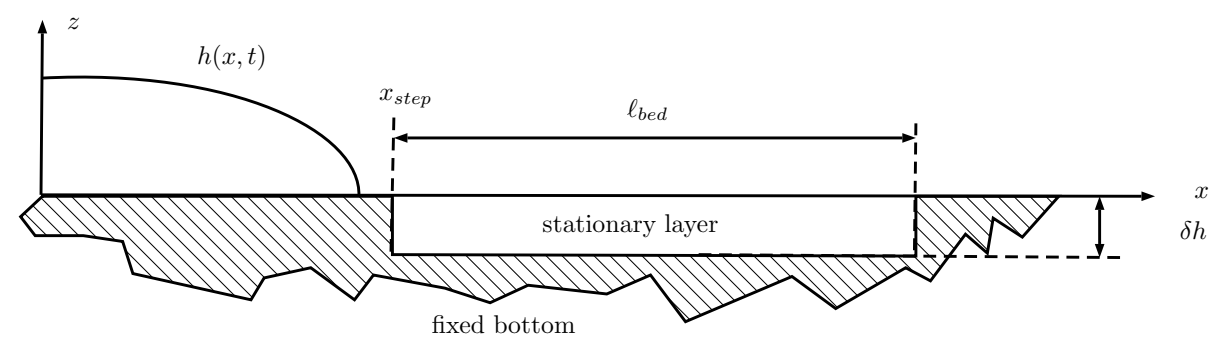

Figure 1: Configuration of the flow. A viscoplastic avalanche is released from a reservoir. It flows over a sloping rigid bed until it gets in contact with a stationary layer made of the same fluid.

To solve this problem, we use lubrication theory. Within the framework of this theory, the momentum balance equations are simplified by neglecting inertia terms and the streamwise gradient of the normal stress. This makes it possible to deduce the pressure and shear stress distributions to the leading order. Making use of the constitutive equation then leads to the velocity profile and, finally, the depth-averaged mass conservation provides the evolution equation for the flow depth $h(x, t)$. There is a large body of work applying this theory to viscoplastic flows $[23,26,27,30,51]$; it is succinctly summarised in the next section.

\subsection{Solution for rigid bottoms}

In the limit of low Reynolds number and small aspect ratio numbers, motion is dictated by the balance between the streamwise gradient of the pressure $\partial_{x} p$, gravitational forces and the cross-stream gradient of the shear stress $\partial_{y} \tau$. To the first order, the pressure $p$ adopts a hydrostatic distribution, while the shear stress $\tau$ follows a linear distribution whose coefficient is controlled by the bed slope and free surface gradient:

$$
p=\varrho g(h-z) \cos \theta \text { and } \tau=\varrho g \sin \theta(h-z)\left(1-\cos \theta \frac{\partial h}{\partial x}\right) .
$$

These expressions hold regardless of the constitutive equation.

We now consider the constitutive equation for simple Herschel-Bulkley materials

$$
\left\{\begin{array}{l}
\dot{\gamma}=0 \text { if } \tau<\tau_{c} \\
\tau=\tau_{c}+\kappa|\dot{\gamma}|^{n} \text { if } \tau \geq \tau_{c}
\end{array}\right.
$$


where $\tau_{c}$ denotes the yield stress, $\dot{\gamma}=\mathrm{d} u / \mathrm{d} z$ the shear rate, $n$ the shear-thinning index (as in most cases $n \leq 1$ ) and $\kappa$ the consistency. These materials flow when the basal-shear stress exceeds the yield stress $\tau_{c}$. When this condition is satisfied, there exists a surface $z=Y(x, t)$ where the shear stress equals the yield stress:

$$
Y=h-\frac{\tau_{c}}{\varrho g \sin \theta\left|1-\cot \theta \frac{\partial h}{\partial x}\right|} .
$$

Below this surface, the fluid is sheared and above this surface it moves like a plug. Equations (2) and (1) lead to the following expression for the streamwise velocity component $u(x, z, t)$

$$
u(x, z, t)=\frac{n}{n+1} A\left(1-S \frac{\partial h}{\partial x}\right)^{1 / n}\left(Y^{1+1 / n}-(Y-z)^{1+1 / n}\right) \text { for } 0 \leq z \leq Y,
$$

with

$$
A=(\varrho g \sin \theta / \kappa)^{1 / n} \text { and } S=\cot \theta .
$$

For $z>Y$, the velocity is constant and equal to the plug velocity $u_{p}=u(x, z=$ $Y, t)$.

Integration of the continuity equation leads to the bulk mass conservation equation

$$
\frac{\partial h}{\partial t}+\frac{\partial h \bar{u}}{\partial x}=0
$$

with $\bar{u}$ the depth-averaged velocity obtained by integration of the velocity field

$$
\bar{u}=\frac{1}{h} \int_{0}^{h} u(x, z, t) \mathrm{d} z=\frac{A}{h} \frac{n Y^{1+1 / n}}{(2 n+1)(n+1)}\left(1-S \frac{\partial h}{\partial x}\right)^{1 / n}(n(h-Y)+(n+1) h) .
$$

\subsection{Extension to erodible bottoms}

At time $t=t_{0}$, the flow front is about to enter the erodible domain, where a layer of fluid is held initially at rest behind a backwards step (see Fig. 1). The stationary fluid lies between $z=0$ and $z=b(x) \leq 0$, defining a rigid base below which entrainment is impossible. 
The problem of basal entrainment can be greatly simplified by considering that the transmission of stress into the bed occurs very quickly, almost instantaneously, and from the outset, the velocity between the overriding avalanche and the bed is continuous. Velocities ar assumed to extend down to the rigid base as soon as $Y>0$ (for both eroding and non-eroding flows). Analysis of Stokes' problems - which study how a fluid layer responds to a sudden solicitation [52-54] - shows that fluidisation occurs nearly instantaneously in shallow viscoplastic layers. Equation (6) can then be extended to varying bottoms (see Appendix A)

$\frac{\partial h}{\partial t}+A \frac{\partial}{\partial x}\left(\frac{n(Y-b)^{1+1 / n}}{(1+n)(1+2 n)}\left(1-S \frac{\partial h}{\partial x}\right)^{1 / n}(n(h-Y)+(n+1)(h-b))\right)=0$.

\subsection{Numerical solution}

We consider a viscoplastic dam-break wave eroding a layer of viscoplastic fluid of thickness $\delta h$ and length $\ell_{\text {bed }}$ (see Fig. 1). We solve Eq. (8), which is a nonlinear, parabolic, partial differential equation, for determining the front position $x_{f}$ and the flow depth profile $h(x, t)$. We used the inbuilt MatLab solver pdepe to do this (the script we used is available from a data repository, see acknowledgements). Note that the Galerkin method [55] used in this solver is unable to cope with shocks. We therefore smoothed the discontinuities in the topography at each end of the step by approximating the step as $b(x)=-\delta h / 2\left(\tanh \left(a\left(x-x_{\text {step }}\right)\right)-\tanh \left(a\left(x-x_{\text {step }}-\ell_{\text {bed }}\right)\right)\right)$ where $a$ is a free parameter. In practice, setting $a=10^{3}$ provided good results (for mesh size $\Delta x=0.5 \mathrm{~mm}$, the thickness of the regularised step was $4 \mathrm{~mm}$, i.e. $8 \Delta x)$. Using no-flux boundary conditions at each end, we solved the governing equation (8) for the flow depth.

Figure 2(a) shows the flow depth evolution for a viscoplastic avalanche released from a reservoir of length $\ell_{r e s}=30 \mathrm{~cm}$ and volume (per unit width) $V_{0}=0.05 \mathrm{~m}^{2}$, in the absence of entrainment $(\delta h=0)$. Figures $2(\mathrm{a}-\mathrm{b})$ show how basal entrainment alters the flow depth profile. The depth of the stationary layer 

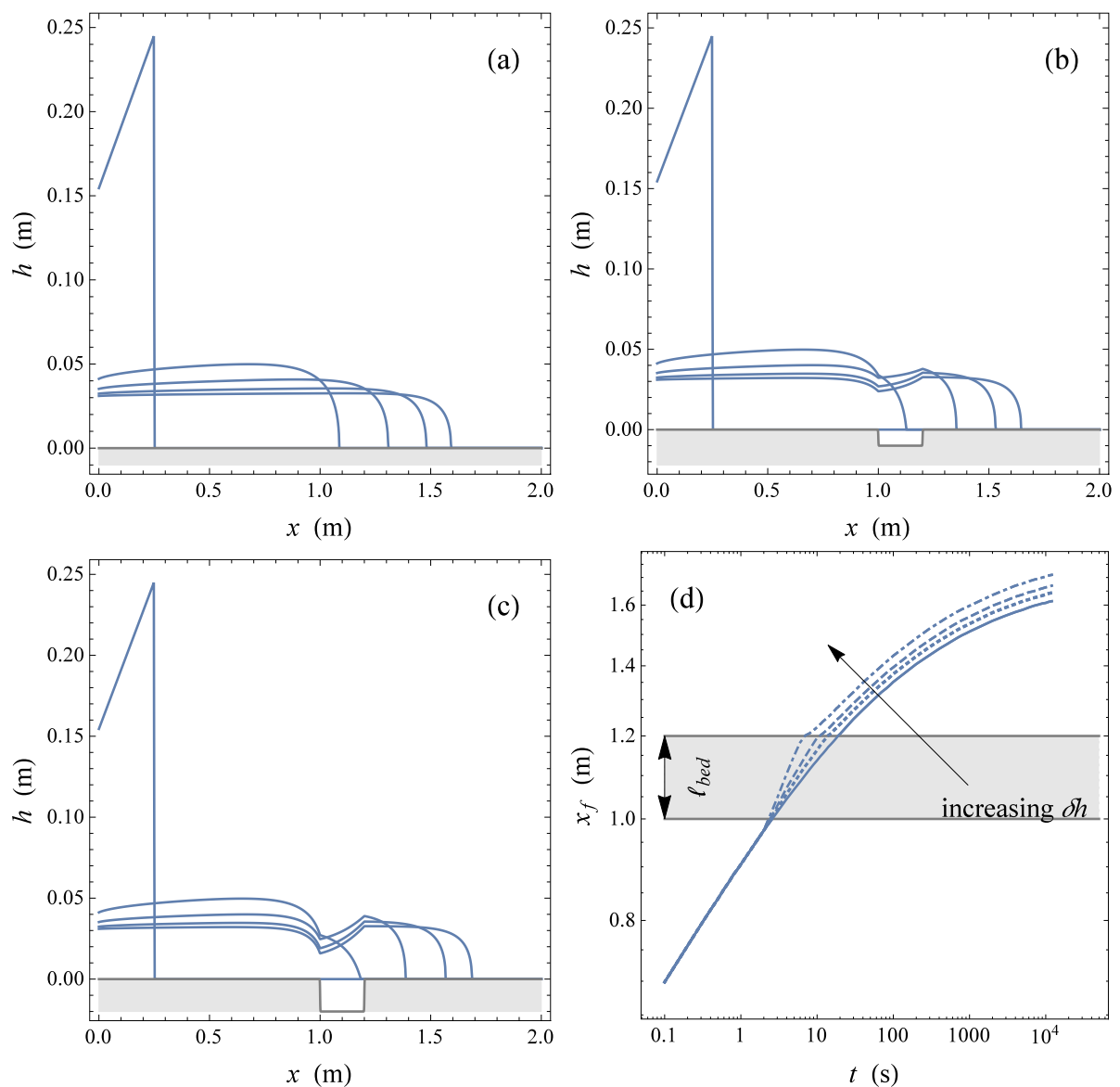

Figure 2: Viscoplastic avalanche over a stationary layer of length $\ell_{\text {bed }}=20 \mathrm{~cm}$. (a-c) Flow depth profiles at times $t=0,6 \mathrm{~s}, 60 \mathrm{~s}, 600 \mathrm{~s}$ and $6,000 \mathrm{~s}$. (a) Bed depth $\delta h=0$ (no entrainment). (b) $\delta h=1 \mathrm{~cm}$. (c) $\delta h=2 \mathrm{~cm}$. (d) Front position with time for different heights $\delta h$ of the stationary layer: solid line $\delta h=0$ (no entrainment), dotted line $\delta h=0.5 \mathrm{~cm}$, dashed line $\delta h=1 \mathrm{~cm}$, dot-dash line $\delta h=2 \mathrm{~cm}$. The grey area indicates the stationary layer. Computations for a Herschel-Bulkley fluid of index $n=1 / 3$, consistency $\kappa=50 \mathrm{Pas}^{1 / n}$, yield stress $\tau_{c}=100 \mathrm{~Pa}$. The initial volume (per unit width) is $V_{0}=0.05 \mathrm{~m}^{2}$ and the slope is $\theta=30^{\circ}$. 
is either $\delta h=1 \mathrm{~cm}$ or $\delta h=2 \mathrm{~cm}$, and its length is the same $\left(\ell_{\text {bed }}=20 \mathrm{~cm}\right)$. When the material flows over the stationary layer, it accelerates, which is reflected by a decrease in the flow depth. The material decelerates as soon as it reaches the fixed bottom. When the front lies over the erodible bed, the flow depth profile is blunter. Figure 2(d) shows the front position with time: the acceleration produced by the stationary layer is clearly visible whereas its deceleration is less marked. The deeper the stationary layer, the more vigorously the front accelerates.

In a previous paper [56] devoted to Newtonian fluids, we investigated the same problem as that presented here. The main difference between viscoplastic and Newtonian fluids is that basal entrainment produces a noticeable increase in the front position in the long run for viscoplastic materials whereas for Newtonian fluids there is little difference between solutions with and without basal entrainment. Indeed, as soon as the front has passed the stationary layer, it undergoes a vigorous deceleration and in the end, there is no difference in the front position between flows with or without basal entrainment. This deceleration is not seen for viscoplastic materials.

The evolution equation (8) exhibits various flow regimes, depending on the relative strength of gravitational forces and yield stress. Two limiting flowregimes can usually be delineated [27]. The diffusive regime occurs over shallow slopes. It refers to flows for which the pressure gradient is counterbalanced by viscous forces (acting in the cross-stream direction). The velocity scale is $U=(\varrho g \cos \theta / \kappa)^{1 / n} H^{1+2 / n} / L^{1 / n}$. The slope-dominated regime corresponds to the limiting flow conditions where the pressure gradient (in the downstream direction) becomes negligible compared to gravitational and viscous forces. The flow then reaches a near-equilibrium regime, where viscous forces balance gravitational forces. The velocity scale is then $U=(\varrho g \sin \theta / \kappa)^{1 / n} H^{1+1 / n}$. The present paper mainly explores the slope-dominated regime. 


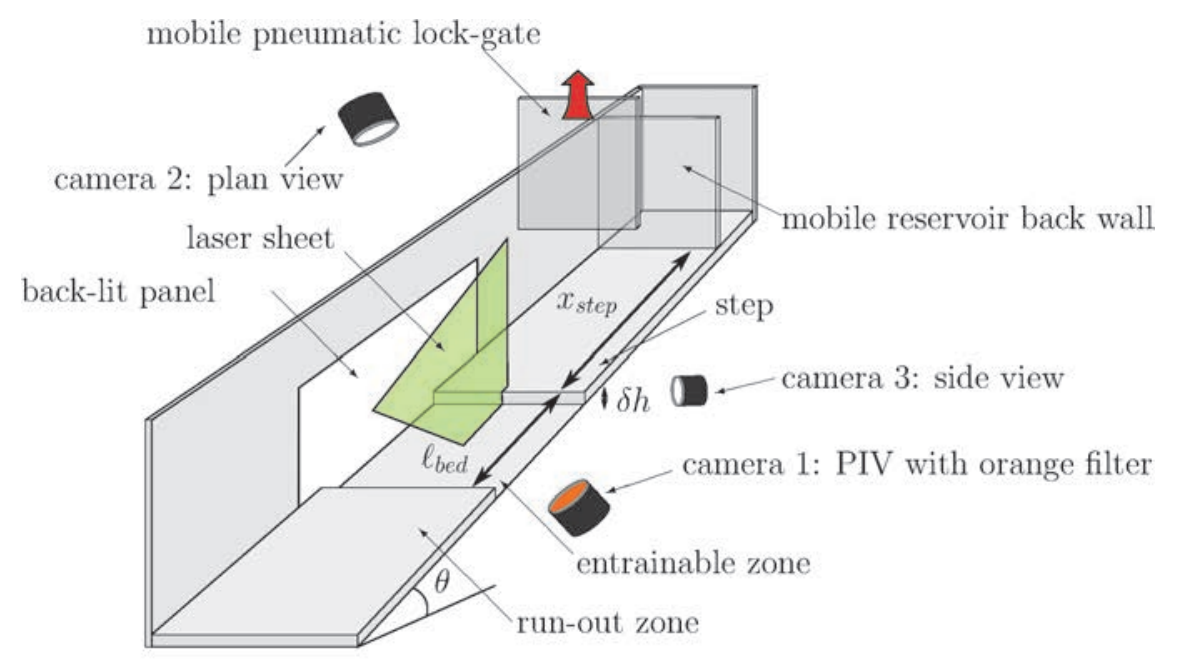

Figure 3: Experimental set-up including reservoir, lock-gate, step and bed, as well as the location of the laser sheet. The flume was tilted at slope angle $\theta$ and the bed dimensions were $\ell_{\text {bed }}$ long by $\delta h$ deep.

\section{Experimental procedure}

\subsection{Flume}

We used a $3.5 \mathrm{~m}$ long, $10 \mathrm{~cm}$ wide, inclinable flume made of a poly(methyl methacrylate) (PMMA), with a $50 \mathrm{~cm}$-long viewing window on each side (see Fig. 3). A mobile pneumatic lock-gate was added in order to release the fluid at the appropriate distance from the viewing window. Two thin sheets of PMMA were placed along the length of the flume, with a gap between the two pieces filled with fluid. In this way, the dam-break wave initially flowed over a rigid base, then over a finite layer of loose material, before continuing over a rigid base again. The distance from the back wall of the reservoir to the erodible layer was denoted by $x_{\text {step }}$. The dimensions of the erodible layer were $\delta h$ deep by $\ell_{\text {bed }}$ long. The holding reservoir's length was fixed at $30 \mathrm{~cm}$. The flume was filmed using three cameras (see Fig. 3 and Sections 3.4 and 3.5). 


\subsection{Fluid}

We used a viscoplastic gel called Carbopol Ultrez 10 (supplied by Lubrizol), prepared as follows: first, powder was added to the required amount of deionised water at $60{ }^{\circ} \mathrm{C}$ and left until it sank to the bottom, for a few hours or overnight; then it was stirred for around two hours and left to settle for a few hours more; finally, an aqueous solution of $\mathrm{NaOH}$ was prepared and mixed with the Carbopol - water solution, in order to neutralise it. It was during this final step that the mixture took on its viscoplastic gel-like appearance. Once prepared, bubbles had to be removed by stirring at a constant, low speed for around one hour.

The Carbopol concentration was set at $0.3 \%$ by weight. The rheological properties were determined using a Bohlin Gemini rotational rheometer. Striated parallel plates, with diameters of $40 \mathrm{~mm}$ and $25 \mathrm{~mm}$, were chosen to reduce slip due to wall depletion effects; gap size was $1 \mathrm{~mm}$. A Herschel-Bulkley constitutive equation (2) was fitted to the rheometrical data. The fluid was found to have the rheological parameters $\kappa=35 \mathrm{~Pa} \mathrm{~s}^{n}, n=0.33$ and $\tau_{c}=58 \mathrm{~Pa}$. The bulk density was $\varrho=997.45 \mathrm{~kg} \mathrm{~m}^{-3}$. Analysing the spread of the rheometric measurements using a $95 \%$ confidence interval gave an error of around $5 \%$ for $\kappa$ and $n$, and around $3 \%$ for $\tau_{c}$.

Throughout, care was taken to remove the bubbles from the fluid and to perform all the experiments as close to $20^{\circ} \mathrm{C}$ as possible. Furthermore, precautions were taken to minimise slip on the PMMA base - any ionic reaction would increase wall depletion, leading to excess lubrication on the base. Coating the flume with Carbopol and letting it dry was found to reduce this effect significantly [57] (at least for non-eroding flows).

\subsection{Experimental protocol}

The mass released, the Carbopol concentration and the slopes used were all chosen so that the surge released from the reservoir flowed easily, while the erodible but stationary layer of fluid in the step stayed still. The bed location was then chosen in order to guarantee that viscous forces were greater 
than inertial forces, $\tau L \sim \kappa L U^{n} / H^{n} \gg \varrho V L / T^{2}$, where $L, H$, and $U$ are the scales for length, height and velocity, respectively: $T=L / U$ and $V=L H$. Then, balancing gravity against viscous forces, $U^{n}=\varrho g \sin \theta H^{n+1} / \kappa$, so that $L \gg\left(\varrho V(g \sin \theta)^{1-n / 2} / \kappa\right)^{2 /(3 n+2)}$. For this reason, the bed began at least $70 \mathrm{~cm}$ downstream for slopes at $12^{\circ}$ and $16^{\circ}$, but at least $90 \mathrm{~cm}$ downstream for slopes at $20^{\circ}$ and $24^{\circ}$. In these experiments, the Bingham number, defined as $\mathrm{Bi}=$ $\tau_{c} /(\varrho g H \sin \theta)$ (with $\left.H \approx 0.03 \mathrm{~m}\right)$, was never greater than 1 . In this regime, the slope effects dominated yield stress effects and thus the shear layer at the base of the flow was significant. This was in comparison with yield-stress dominated flows, in which the pseudo-plug extended almost to the base [27].

Two sets of experiments were carried out. In one set, particle image velocimetry experiments were conducted to identify any internal changes due to entrainment. Table 1 shows the main features of this set. In the other set, the fluid was stained with methylene blue so that the flow front could be tracked down the length of the flume and surface height measurements could be made. Table 2 shows the main features of this campaign.

Three types of experimental run were performed, denoted as $0, \mathrm{R}$ or $\mathrm{C}$ in Tables 1 and 2. The 0 runs corresponded to cases with no entrainment base, where the dam-break flowed over a rigid base all the way down the channel. The R (reservoir) runs involved fluid stained with methylene, or seeded with rhodamine-tagged particles, and released from the reservoir, whereas the entrainable bed was made of clear fluid (unseeded, unstained): this configuration allowed us to study the surge/bed interface. The $\mathrm{C}$ (combined) runs contained rhodamine-tagged seeds everywhere so that the velocity field could be obtained in the bed and the surge. Examples of the images obtained in the $\mathrm{C}$ and $\mathrm{R}$ runs are shown in Fig. 5. These various runs made it possible to determine the positions of key points: point $\mathrm{F}$ (front position $x_{f}$ at which the flow depth satisfies $h\left(x_{f}\right)=0$ ) and point $\mathrm{K}$ (lying at the intersection between the free surface and the "contact discontinuity", which is the interface separating the incoming and stationary fluids). We refer to $d_{\max }$ as the maximum penetration depth of the incoming fluid (see Fig. 4). 


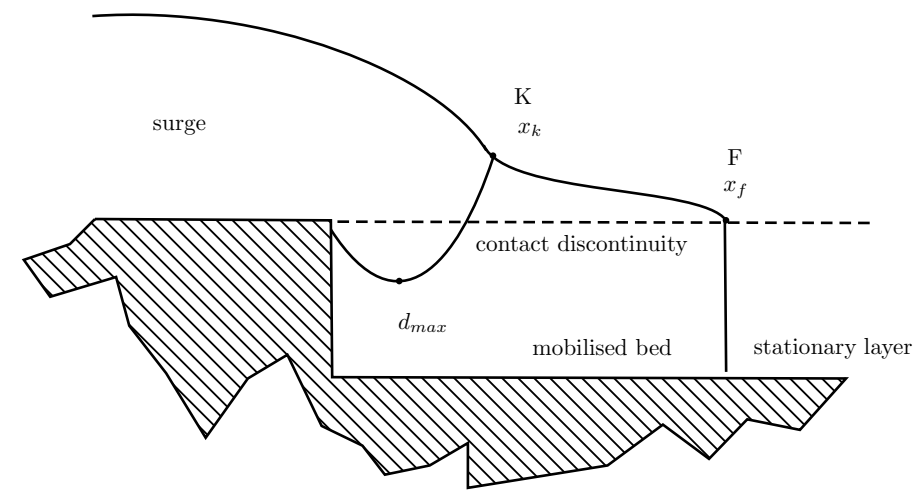

Figure 4: A material surface, called the "contact discontinuity", separates the surge from the bed material. Experimentally, this interface can be tracked by using fluids of different colours. The front (point F) is the point of furthest reach, at which the flow depth drops to zero. The intersection of the contact discontinuity and free surfaces is represented by point $\mathrm{K}$ (where the flow depth profile displays a kink).

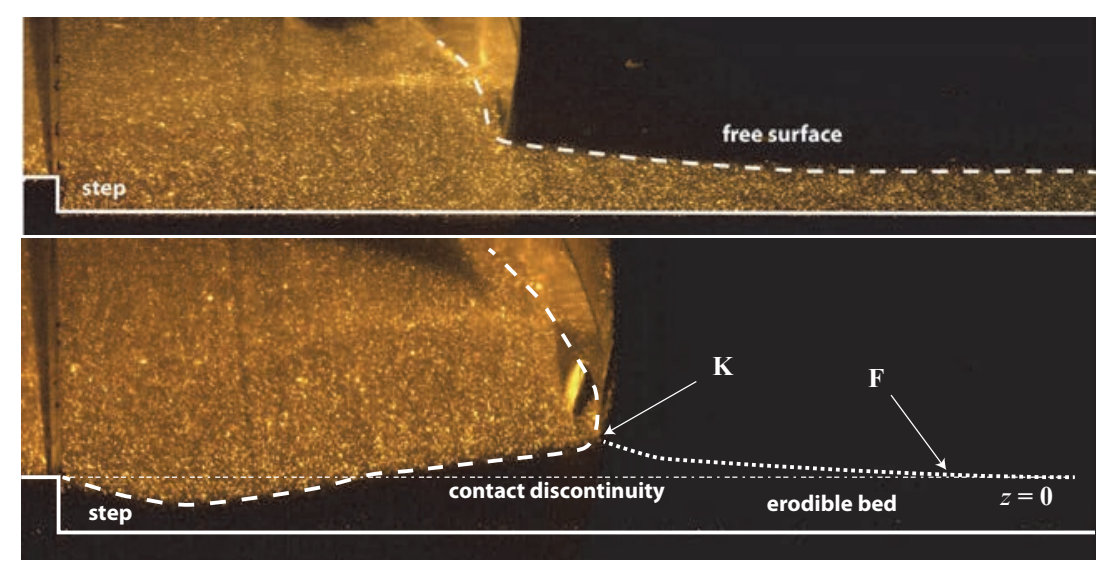

Figure 5: Images from Camera 1 (side views). These images show the fluid seeded with rhodamine. The step marking the transition from rigid base to entrainable bed is clearly visible in the bottom left-hand corner of the images. The dashed line highlights the free surface (as the image was taken from below as shown in Fig. 8, part of the free surface behind the laser sheet is visible). Top image: "C", or combined run, with seeding in both the surge and the entrainable material. Bottom image: "R", or reservoir run, in which only the dambreak was seeded. In this high-contrast image, it is difficult to identify the position of the free surface, but this is easier in the raw images. Points $\mathrm{K}$ and $\mathrm{F}$ are also marked. 
Table 1: Experiments performed to obtain internal velocity measurements (Carbopol-seeded for particle image velocimetry). Slope $\theta$, bed thickness $\delta h$, mass released $M$, position of the step $x_{\text {step }}$, length of the step $\ell_{b e d}$, fluid temperature $T$.

\begin{tabular}{rcccccc}
\hline run name & $\theta\left[^{\circ}\right]$ & $\delta h[\mathrm{~mm}]$ & $M[\mathrm{~kg}]$ & $x_{\text {step }}[\mathrm{cm}]$ & $\ell_{\text {bed }}[\mathrm{cm}]$ & $T\left[{ }^{\circ} \mathrm{C}\right]$ \\
\hline $12-0 \mathrm{a}$ & 12 & 0 & 3 & 70 & - & 20.0 \\
$12-6 \mathrm{Ra}$ & 12 & 6 & 3 & 70 & 30 & 20.35 \\
$12-6 \mathrm{Ca}$ & 12 & 6 & 3 & 70 & 30 & 20.25 \\
$16-0 \mathrm{a}$ & 16 & 0 & 3 & 70 & - & 20.0 \\
$16-0 \mathrm{~b}$ & 16 & 0 & 3 & 90 & - & 19.8 \\
$16-6 \mathrm{Ra}$ & 16 & 6 & 3 & 70 & 30 & 19.9 \\
$16-6 \mathrm{Ca}$ & 16 & 6 & 3 & 70 & 30 & 19.65 \\
$16-6 \mathrm{Cb}$ & 16 & 6 & 3 & 90 & 30 & 19.7 \\
$20-0 \mathrm{a}$ & 20 & 0 & 3 & 90 & - & 19.7 \\
$20-6 \mathrm{Ra}$ & 20 & 6 & 3 & 90 & 30 & 20.15 \\
$20-6 \mathrm{Ca}$ & 20 & 6 & 3 & 90 & 30 & 20.0 \\
$24-0 \mathrm{a}$ & 24 & 0 & 3 & 90 & - & 19.6 \\
$24-6 \mathrm{Ra}$ & 24 & 6 & 3 & 90 & 30 & 19.6 \\
$24-6 \mathrm{Ca}$ & 24 & 6 & 3 & 90 & 30 & 19.75 \\
\hline
\end{tabular}

\subsection{Bulk measurements}

To obtain bulk measurements, methylene blue-stained Carbopol was used against a white background and a back-lit side panel, as shown in Fig. 6. Camera 2 (a Basler A403k) filmed from above to show the progression of the flow front. Camera 3 (a Basler acA2000-165um) filmed through the observation panel on the side of the flume to obtain the flow depth profile and front position during entrainment. An LED panel provided backlighting. Three configurations were used: $0, \mathrm{R}$ and $\mathrm{C}$, as described above and indicated in Table 2.

Using the calibration grids, the resolutions of cameras 2 and 3 were roughly 2 and 3 pixels per mm, respectively. Thus, measurements from these two cameras (surface height and flow front position) can be estimated to be accurate to within $0.5 \mathrm{~mm}$, taking into account effects such as shadows on camera 2 and surface curvature on camera 3 .

In the experiments detailed in Table 2, camera 2 filmed a bird's eye or plan view of the flows down the length of the flume, and from these images it was 


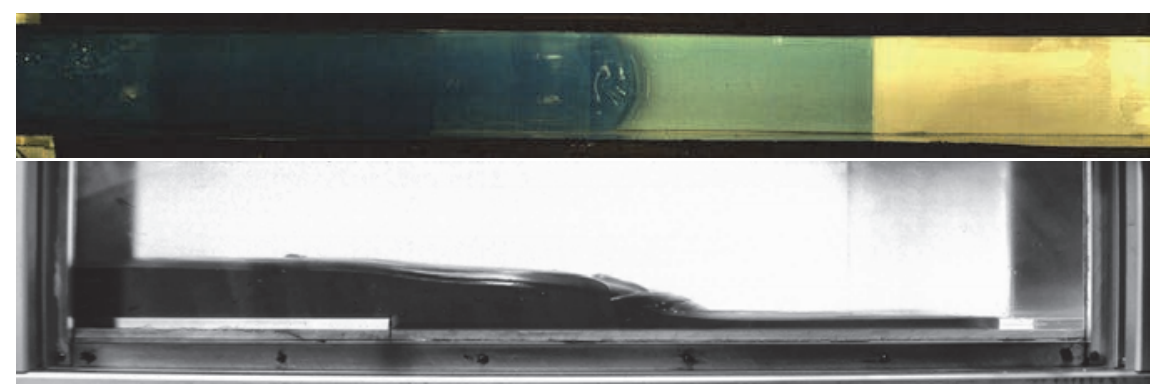

Figure 6: Images from camera 2 (top) and camera 3 (bottom). Camera 2 took plan views of the flow during entrainment, whereas camera 3 took side views. Combined experiment 20-6Ca, at $20^{\circ}$ with entrainable bed dimensions of $6 \mathrm{~mm}$ deep by $30 \mathrm{~cm}$ long.

possible to isolate the front position $x_{f}$. Figure 7 shows time-space plots of the flow, created by sampling a central line of pixels in the image at each time step. When the front was outside the erodible bed, the front position was deduced from this time--space plot using image processing techniques in MatLab. Over the erodible bed, the front position was determined using camera 3's images.

\subsection{Internal measurements}

Particle image velocimetry (PIV) was performed on images obtained at a vertical laser sheet parallel to the flow direction. The images were obtained by using a 2 W Diode-Pumped Solid State Nd:YAG laser with a $532 \mathrm{~nm}$ wavelength in the optical set-up shown in Fig. 8. This laser created the vertical laser sheet in the observation zone, which illuminated rhodamine-stained seeds in the flow. The seeds used in this study were $20 \mu \mathrm{m}$ PMMA beads tagged with rhodamine $6 \mathrm{G}$, a stain which was fluorescent in green light. In this way, only the particles in the central laser sheet were illuminated and only they were filmed. The concentration of these particles was very small, with less than a level teaspoon of particles for $3 \mathrm{~kg}$ Carbopol.

Camera 1 (a Basler A403k) filmed the illuminated internal section of the flow through an orange filter. This resulted in the images shown in Fig. 5 in which the seeds glow as bright dots against a black background. The camera was placed below the flume and filmed through the transparent base and a prism, using 


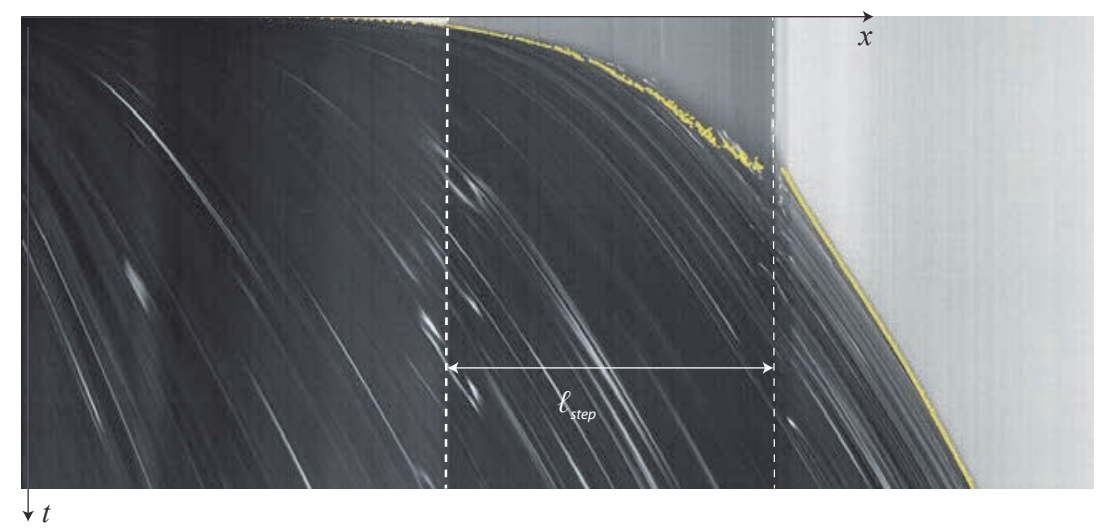

Figure 7: Time-space plots from camera 2, showing front progression for experiment 16-3Cc. A central row of pixels (in yellow) has been sampled at each time step and repeated vertically to create these plots. The front position was found using a series of image processing functions. For $x_{\text {step }} \leq x \leq x_{\text {step }}+\ell_{\text {bed }}$, this method failed (it could only provide the position of point $\mathrm{K})$; in this case, front position was determined from images taken using camera 3 .

a tilted lens in accordance with the Scheimpflug principle in order to obtain clear images from a focal plane which was non-parallel to the image plane [58]. Usually, PIV is performed by filming from the side, but the flow front in many of these experiments was significantly curved in the cross-stream direction, and so images were acquired through the base in order to avoid distortion at the flow front. Camera 1 was calibrated for each experiment using a grid immersed in the fluid in the flume. PIV measurements were taken in a $6.5 \mathrm{~cm}$-long central stream-wise section in the entrainment zone.

Velocity fields were calculated using PIV between two images set an appropriate time-step apart. The PIV software used was the MatPIV open-source package [59]. The velocity field was then filtered to remove vectors with a signalto-noise ratio below 1.3 - this ratio is an output from MatPIV, giving a measure of signal reliability in each interrogation window. Then, an in-built local filter was used to remove velocity vectors deviating from their neighbours' median velocity vectors by more than the recommended factor of 2.7 times the neighbours' standard deviation. Finally, all the vectors removed were interpolated linearly. All measurements were corrected for perspective using a calibration 


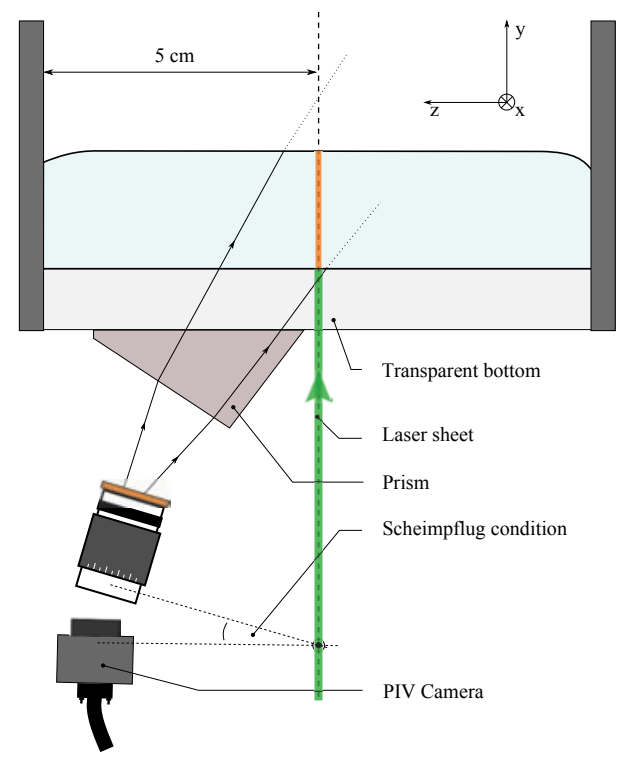

Figure 8: Sketch of the measurement system for the velocity profiles within the moving fluid. Because of the fluid-air interface and the three-dimensional nature of the flows, we were forced to film the flow from below. When shooting images with a camera whose sensor is not parallel with the object one can use the Scheimpflug principle, which involves tilting the camera until the image plane (on the CCD), the lens plane and the object plane (lit by the laser sheet) have a common line of intersection. Taken from [57]. 
grid. Error quantification in PIV remains difficult, but it is known that strong velocity gradients reduce measurement accuracy [60], so steps were taken to minimise errors, such as choosing the optimum seeding density and correlation window size.

\section{Experiments}

We begin by analysing the experiments performed to investigate the bulk dynamics of entraining viscoplastic surges (see Table 2): the flow front position $x_{f}(t)$ and the flow depth profile $h(x, t)$ are studied and compared with the numerical solutions to the evolution equation (8). Then, we present the internal measurements to understand the mechanisms underlying basal entrainment in viscoplastic flows.

\subsection{Bulk measurements}

Figure 9(a) shows the effects of the entrainable bed thickness on front propagation for runs 16-0c, 16-3Cc, 16-6Cc and 16-9Ca. Clearly, the entrainable layer's depth is an important controlling parameter as the flow front travels further over an entrainable bed than over the rigid base, and this effect increases significantly with the depth of entrainable material. This contrasts with what we observed with Newtonian flows in a similar experimental configuration [56].

A longer entrainable bed also causes the flow-front position to be further advanced compared to non-eroding flows, in a roughly linear way. For example, in Fig. 9 (b) the flow fronts are approximately $2 \mathrm{~cm}, 5 \mathrm{~cm}$ and $8 \mathrm{~cm}$ further advanced for bed lengths of $10 \mathrm{~cm}, 20 \mathrm{~cm}$ and $30 \mathrm{~cm}$ respectively. In some experiments, the position $x_{\text {step }}$ of the entrainable bed was varied but these comparisons provided no clear conclusion.

Figure 10 compares measured and computed front positions for runs $12-6 \mathrm{Ca}$ and 16-6Cc. Equation (8) was solved numerically using the built-in Matlab pdepe function. As described in earlier publications [61, 62], lubrication theory overestimates front position over time. Several processes can explain the 

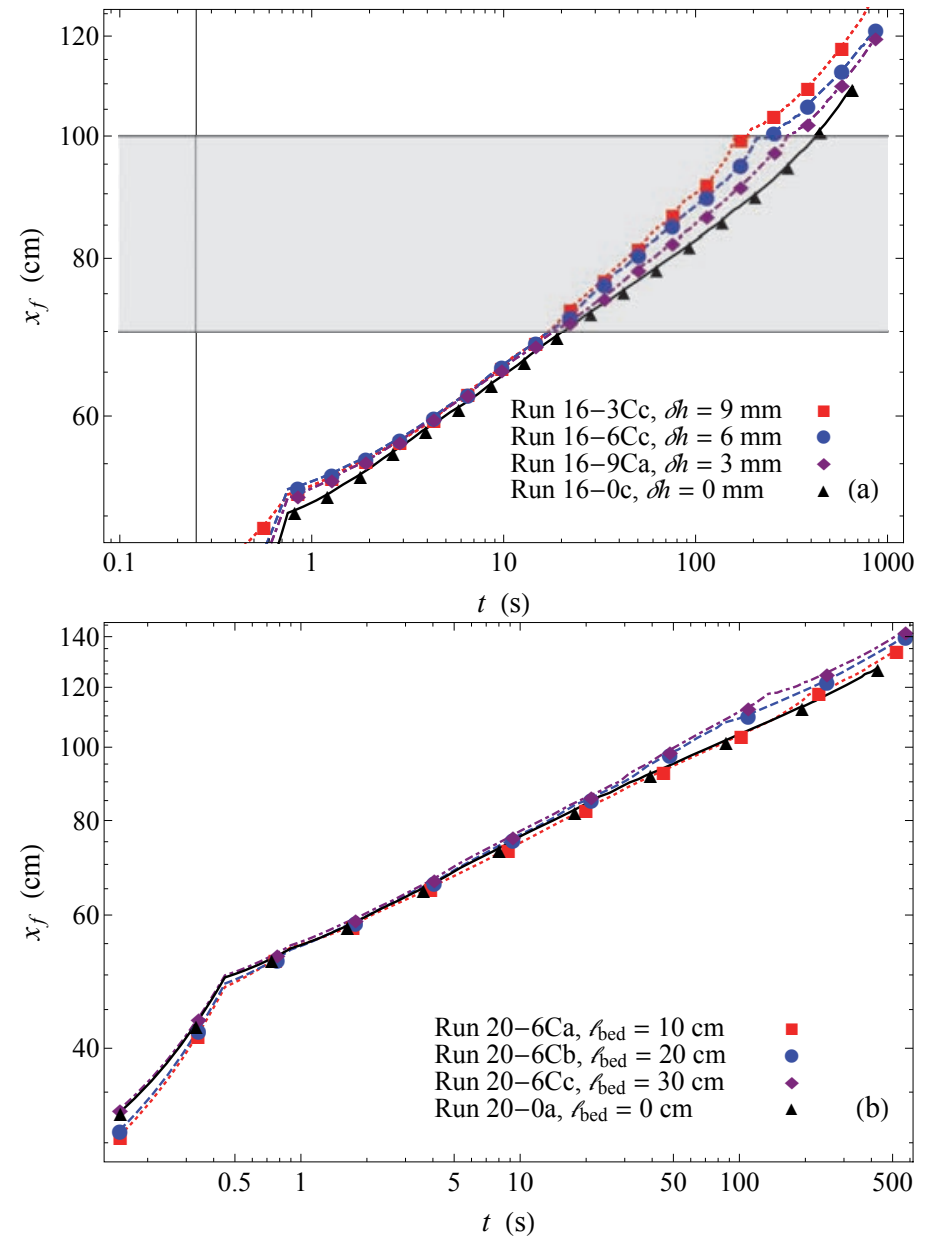

Figure 9: (a) Front position with time for flows over entrainable beds of increasing depth: $\theta=16^{\circ}$ slope, $\ell_{\text {bed }}=30 \mathrm{~cm}$ (the entrainable layer is indicated by the grey area). (b) Front position with time for flows over entrainable beds of increasing lengths with $\delta h=6 \mathrm{~mm}$ and $\theta=20^{\circ}$. 


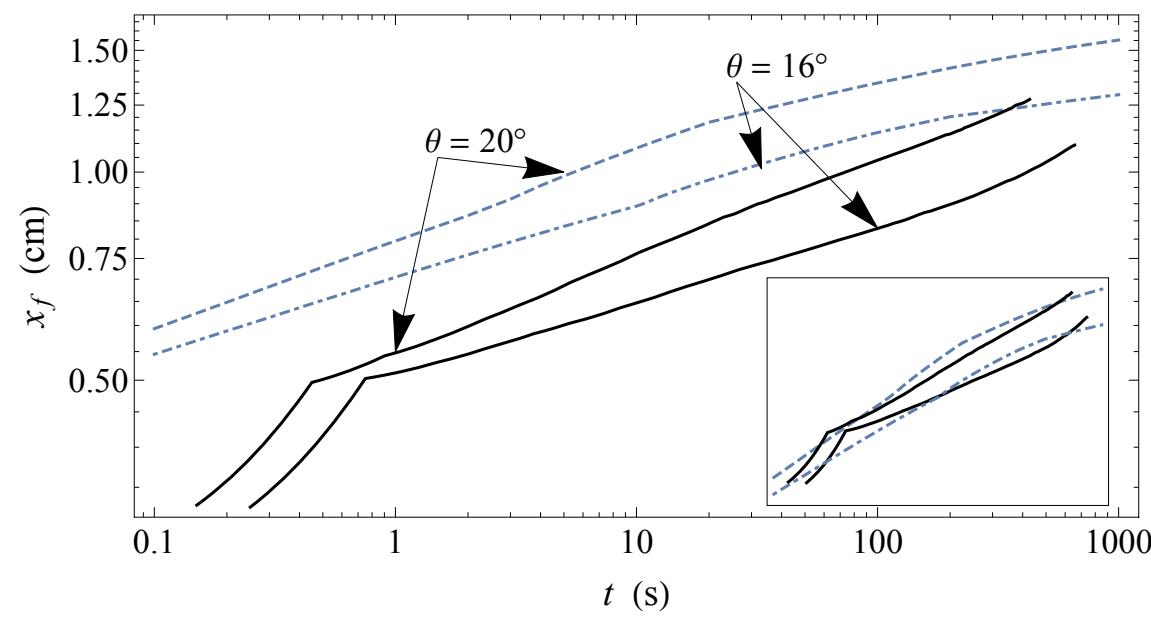

Figure 10: Front position with time for flows for $\theta=16^{\circ}$ (Run 16-6Cd) and $\theta=20^{\circ}$ (Run 206Ca). Parameters: $x_{\text {step }}=90 \mathrm{~cm}, \delta h=6 \mathrm{~mm}$ and $\ell_{\text {bed }}=30 \mathrm{~cm}$. The black solid lines show the front position measured experimentally. The dotted-and-dashed line shows the numerical solution for $\theta=16^{\circ}$, while the dashed line shows the numerical solution $\theta=20^{\circ}$. The inset shows the numerical and experimental data after shifting the observed front positions by $+25 \mathrm{~cm}$.

systematic deviation between theory and experiment: increased flow resistance due to sidewalls, lubrication theory's poor performance at describing the inertial phase when the gate lifts up and the material is released, and the specific behaviour of the leading edge - theory predicts that the yield surface terminates at the front (as a first approximation), whereas experiments show that the tip region is entirely sheared $[61,62]$. There is a systematic shift, with the numerical solution $25 \mathrm{~cm}$ ahead of the experimental curve. Apart from this shift, the numerical data roughly captured the experimental trend, as shown by the inset of Fig. 10, although it did not capture all the details.

This systematic deviation between theory and experiment - even in the absence of entrainment - makes it difficult to assess how good lubrication theory is at describing the effect of basal entrainment. We expected that by making the flow variables dimensionless, we could compare experimental results more easily, but this was not the case: the curves of front position against time did not 

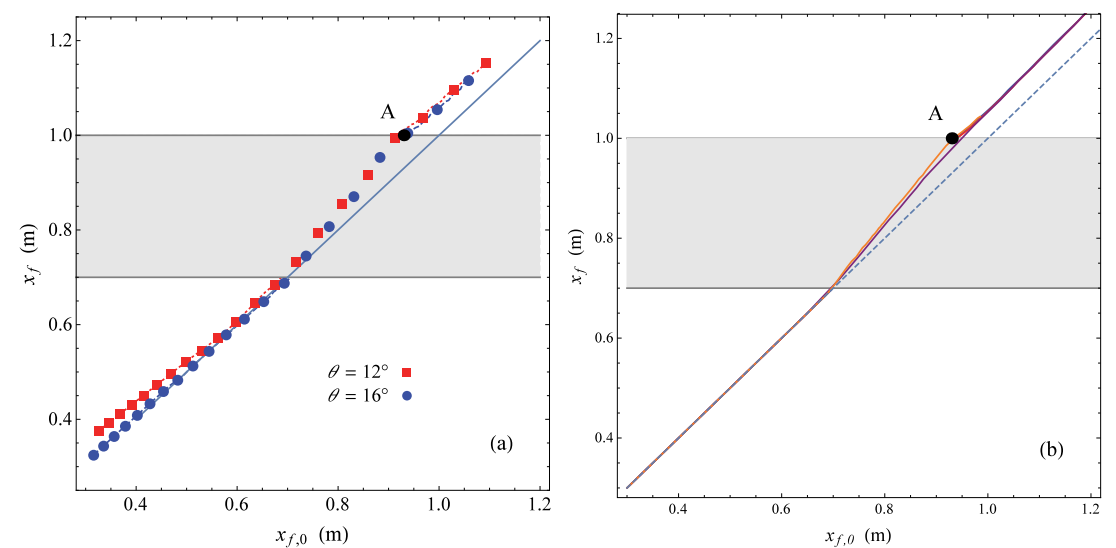

Figure 11: (a) Front position for flows over entrainable beds: $\theta=16^{\circ}$ (run 16-6Cd) and $\theta=12^{\circ}$ (run 12-6Ca). The front position has been plotted as a function of the position $x_{f, 0}(t)$ it occupies with no entrainment. (b) Front position for entraining flows as a function of $x_{f, 0}$ (front position in the absence of entrainment). Numerical computations done for $\theta=12^{\circ}, \theta=16^{\circ}, \theta=20^{\circ}$ and $\theta=24^{\circ}$. The coordinates of point A are $(0.94,1) \mathrm{m}$.

collapse as the dimensionless flow-front travelled faster on steeper slopes. Thus, in order to examine the effect of flume inclination on entrainment, we plotted the flow-front position of an entraining flow as a function of its equivalent nonentraining flow front denoted by $x_{f, 0}(t)$. This gave a direct measurement of the effects of the entrainable material. Figure 11(a) shows clearly that the effects of entrainment on the surge are similar at each inclination. For each slope, the curves show that the flow front has advanced further due to entrainment, and they all collapse neatly on top of each other.

Figure 11(b) shows how the front position varies as a function of $x_{f, 0}$ in the numerical solutions to the governing equation (8). Similarly to the experiments, the curves $x_{f}\left(x_{f, 0}\right)$ computed for slopes from $12^{\circ}$ to $24^{\circ}$ almost collapse on the same master curve. The agreement between plots 11(a) and 11(b) is surprisingly good (given the discrepancies shown in Fig. 10). To facilitate comparison, we report point A (with coordinates $(0.94,1) \mathrm{m}$ ) in both figures. This point marks the end of the entrainable layer. Numerical solutions show that the front position of eroding flows is $6 \mathrm{~cm}$ ahead of the front position in the absence of entrainment, 


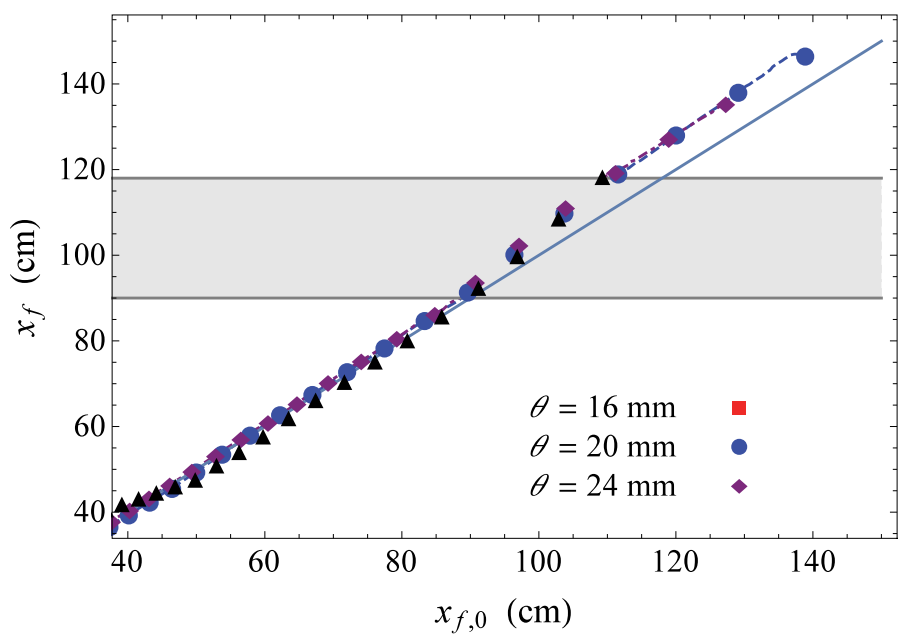

Figure 12: Front position for flows over entrainable beds: $\theta=16^{\circ}$ (run 16-6Cd), $\theta=20^{\circ}$ (run 20-6Ca) and $\theta=24^{\circ}$ (run 24-6Ca). The $30 \mathrm{~cm}$-long bed is indicated by the grey area.

and this is in agreement with the value found experimentally. Although this is not clearly visible in the figures, the curves do not collapse completely on a single master curve. This reflects the influence of flume inclination, but as this effect is barely visible we can conclude that slope influence is negligible. Further experiments confirm this behaviour (see Fig. 12).

The shape of the surge is qualitatively well reproduced by the evolution equation (8), with a hollowed-out surface above the entrainable bed. Figure 13 shows an example of this qualitative agreement: there is a large kink in the surface near the step, the surface height upstream of the bed decreases in agreement with the modelled profile and the front shape is quite well reproduced, although the times at which the experimental measurements are plotted do not correspond to those for the model and not all the experimental observations were reproduced. Indeed, the experimental measurements showed a small, second surface kink where the contact discontinuity separated surge fluid from uplifted bed fluid in the leading edge (see also Fig. 4, the kink corresponds to point K). This is visible in the experimental profiles shown in Fig.13. Lubrication theory provides smooth profiles with no kinks. 


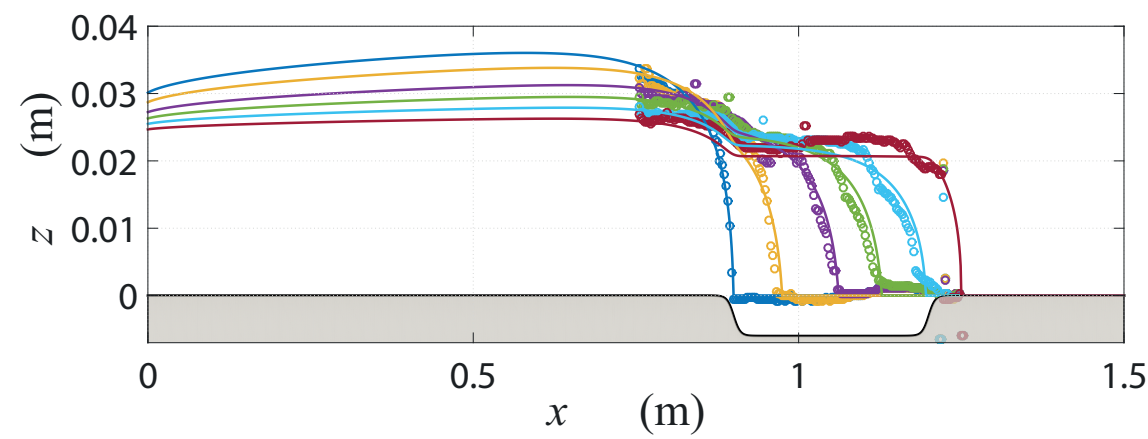

Figure 13: A comparison of surface height profiles between an experiment and a numerical simulation. Measurements taken during the flow front's journey across the bed surface. Experiment shown is run 20-6Ca: $\theta=20^{\circ}, \ell_{b e d}=30 \mathrm{~cm}, \delta h=6 \mathrm{~mm}$ deep. Here, the profiles are chosen to show the similarity of the surface shape, but the significant lag in the modelled flow means that this comparison remains qualitative only.

\subsection{Internal measurements}

Experiments were performed specifically to be able to observe and quantify the flow's internal velocities, concentrating precisely on the zone just downstream of the step in order to see how the surge interacted with the entrainable material.

As a first step, we examined the raw images in order to infer a qualitative impression of the flow's progression. Figure 14 shows the velocity fields from run 16-6Ca, where $3 \mathrm{~kg}$ of Carbopol was released and entrained a region of entrainable fluid $6 \mathrm{~mm}$ deep by $30 \mathrm{~cm}$ long. Velocities were made dimensionless by scaling them with $U=\left(\varrho g \sin \theta H^{n+1} / \kappa\right)^{1 / n}$ [63], with $H$ kept constant at $0.03 \mathrm{~m}$. The lengths were scaled by $L=1 \mathrm{~m}$. Figure 14 shows the progression of the viscoplastic surge as it comes into contact with the erodible stationary layer:

- The surge initially rolls out a short distance onto the entrainable bed with an immediate, but local effect on the bed material: the bed surface is deformed slightly, moving downwards and forwards in the vicinity of the front. There is strong shear at the surface of the entrainable bed, with almost plug-flow above and low streamwise velocities in the bed. 
- A region of significant downward motion is established next to the step as the bed moves under the surge's weight. This displaces bed material downstream, squeezing it between flowing material upstream and stationary material downstream. As a result, a wedge shaped region downstream of the surge interface (contact discontinuity) begins to move upwards.

- The surge continues to drive forwards across the entrainable bed. Its interface remains pronounced, with an indentation in the flow surface where it meets the bed (point K). A bump appears in the bed as bed material moves upwards.

- As time progresses, the bed surface is uplifted almost in line with the surge interface, but the indentation here is still visible. The bed material is in motion much further downstream of this point. The flow front $x_{f}$ is much further downstream than kink point $x_{k}$ due to the bed uplift, and motion occurs right down to the rigid base.

We did not observe a static-flowing interface (except in the lower-left corner of the step), but instead saw a continuous velocity field in the entrainable material with a smooth variation between erodible-but-stationary and mobile material. In the vertical direction, the material was quickly entrained down to the rigid base and the entire bed was set into motion. In the streamwise direction, things were less clear-cut: the streamwise velocity component $u(x, z, t)$ continuously decreased to zero with increasing $x$, but it was difficult to determine the exact position at which $u=0$, due to the uncertainties in our PIV measurements. To get around this issue, we determined the velocity contour lines and sought the point of furthest reach for each contour. Figure 15 shows how distant this point is from point $\mathrm{K}$ for run 20-6Ca. We chose four dimensionless threshold streamwise velocities: $\hat{u}=u / U=0.2 \times 10^{-3}, 0.5 \times 10^{-3}, 10^{-3}$ and $2 \times 10^{-3}$. The bed was progressively put into motion in the streamwise direction, and the velocity increased very gradually. At steeper slopes, the bed material was entrained more quickly than the surge interface (point $\mathrm{K}$ ): the right-hand plot shows that threshold velocities were breached further downstream than 


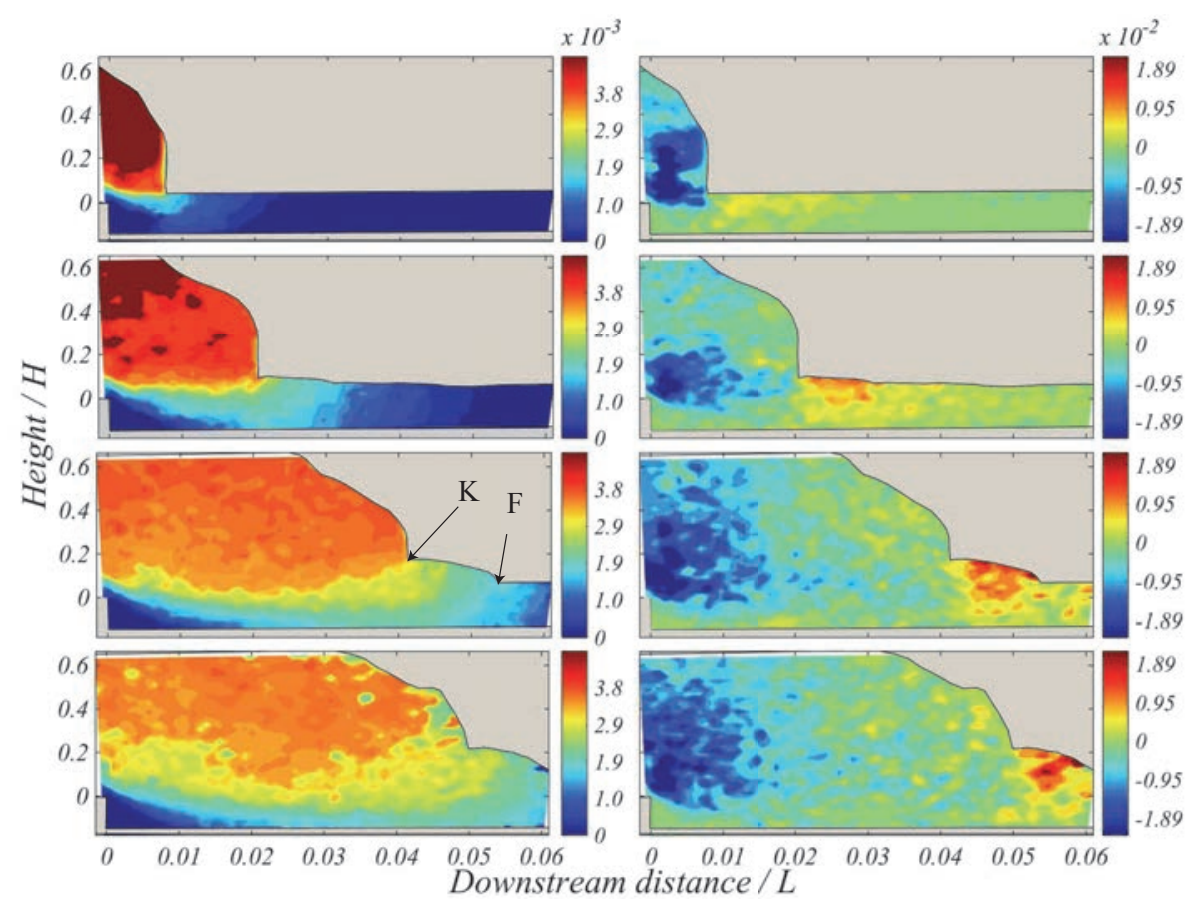

Figure 14: Dimensionless velocity fields for streamwise (on the left) and slope-normal (on the right) velocity components. 16-6Ca: $16^{\circ}$ slope, $6 \mathrm{~mm}$ deep by $30 \mathrm{~cm}$ long entrainable bed. Plotted at times $3.75 \mathrm{~s}, 10.5 \mathrm{~s}, 24 \mathrm{~s}$ and $30.75 \mathrm{~s}$ after the surge's entry into the entrainable region. The step is shown in bottom left-hand corner. The arrows point to the points $\mathrm{K}$ (interface of the incoming fluid) and $\mathrm{F}$ (front at which $h=0$ ). 

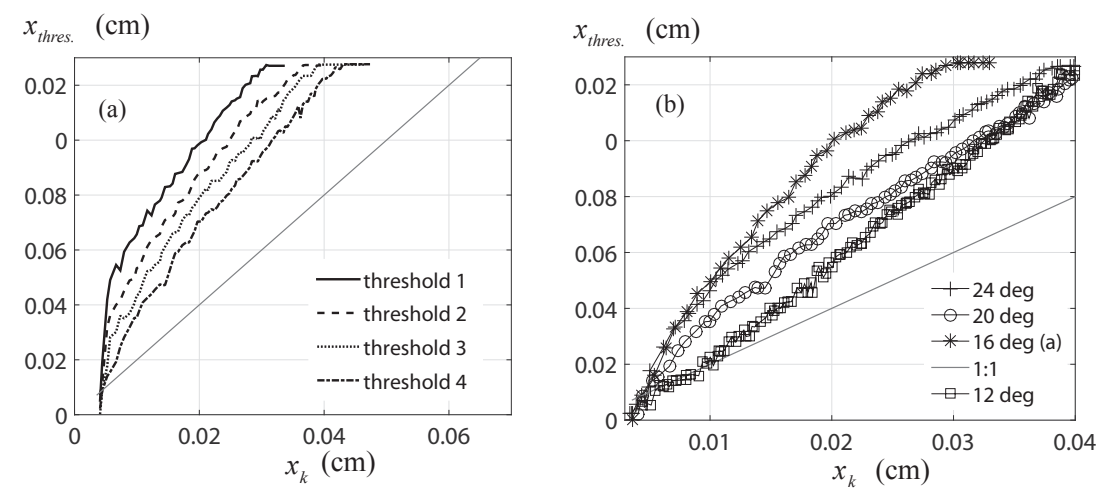

Figure 15: (a) variation in the position of the furthest downstream point $x_{t h r e s}$. (at which a velocity threshold is breached) with the kink point's abscissa $x_{k}$ (point $\mathrm{K}$ at which the contact discontinuity surface connects with the free surface, see Fig. 4) for run 20-6Ca. The threshold point is computed for four non-dimensional threshold streamwise velocities: $0.2 \times$ $10^{-3}$ (threshold 1), $0.5 \times 10^{-3}$ (threshold 2), $10^{-3}$ (threshold 3 ) and $2 \times 10^{-3}$ (threshold 4). (b) Variation in the position of the furthest downstream point associated with $\hat{u}=0.2 \times 10^{-3}$, with the kink point's abscissa $x_{k}$ for all slopes. Experimental conditions: $\ell_{\text {step }}=0.7 \mathrm{~m}$ for $\theta=12^{\circ}$ and $16^{\circ}$, whereas $\ell_{\text {step }}=0.9 \mathrm{~m}$ for $\theta=20^{\circ}$ and $24^{\circ}$.

point $\mathrm{K}$ at $24^{\circ}$ and $16^{\circ}$ than at $20^{\circ}$ and $12^{\circ}$, respectively. This supports the idea that a wave (called an acceleration wave [64]) propagated downstream of the contact discontinuity and was associated with bed entrainment.

Internal dynamics are likely to vary with slope inclination. In Fig. 16, velocity fields are compared qualitatively for different slopes. With the surge interface in a similar place in each plot, even a non-dimensionalisation in line with the slope-dominated regime is not enough to account for the variation in velocities. Aside from the magnitude of the velocity, the flows' viscoplastic behaviours also differed with the slope. At $12^{\circ}$, much of the flow was a plug, with a thin region of strong streamwise shear and likely slip on the rigid base. However, the shear layers were thicker at steeper slopes. The consequence was that at shallower slopes, the surge intruded more deeply into the bed, effectively bulldozing a thick layer of bed material downstream and causing the bed to buckle and slip along its base. This is perhaps intuitive, as on a steeper slope the streamwise component of gravity becomes more important and the component directed into 


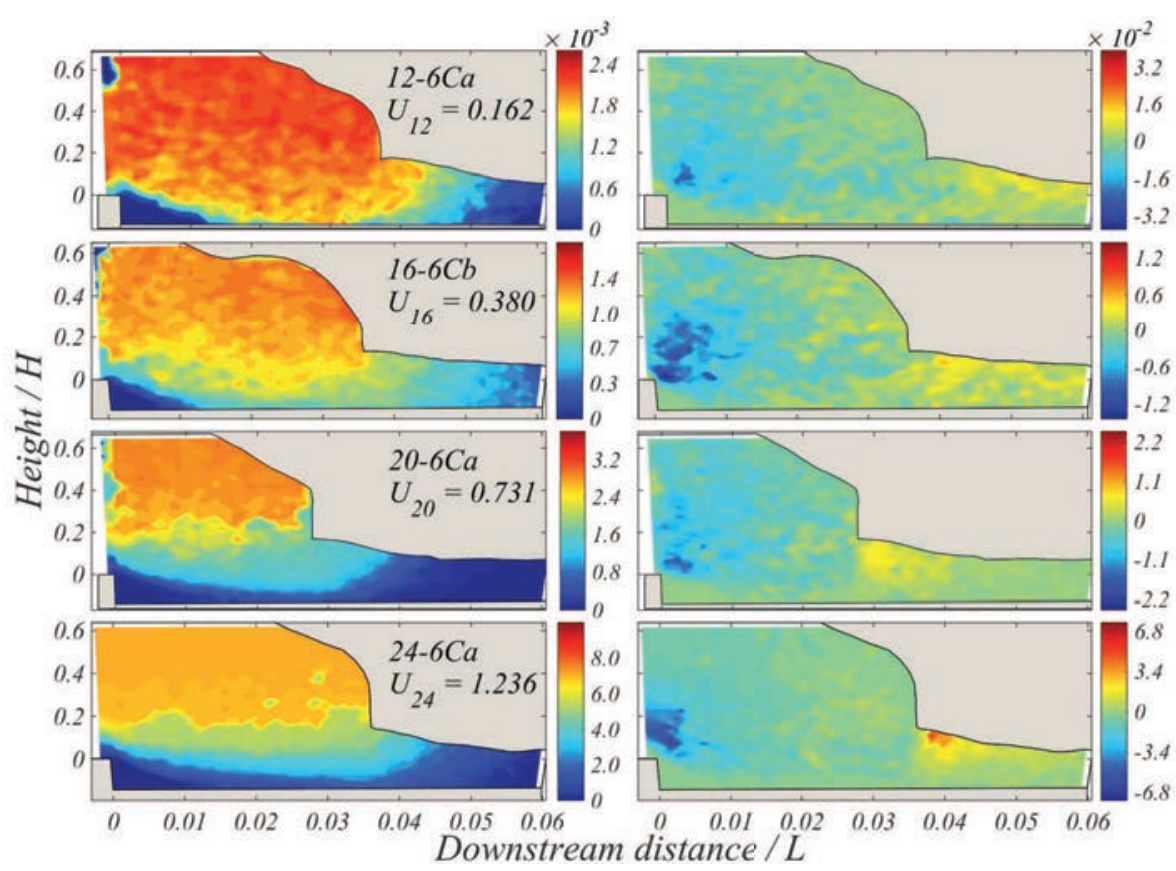

Figure 16: Dimensionless velocity fields for streamwise (left) and slope-normal (right) velocity components for run $12-6 \mathrm{Ca}\left(\theta=12^{\circ}\right)$, bed at $70 \mathrm{~cm}$; run $16-6 \mathrm{Cb}\left(\theta=16^{\circ}\right)$, bed at $90 \mathrm{~cm}$; run $20-6 \mathrm{Ca}\left(\theta=20^{\circ}\right)$, bed at $90 \mathrm{~cm}$; and run $24-6 \mathrm{Ca}\left(\theta=16^{\circ}\right)$, bed at $90 \mathrm{~cm}$. The step is shown in bottom left-hand corner. In each subplot, we report the velocity scale $U$ (in $\mathrm{m} / \mathrm{s}$ ), used for making the velocity dimensionless. 


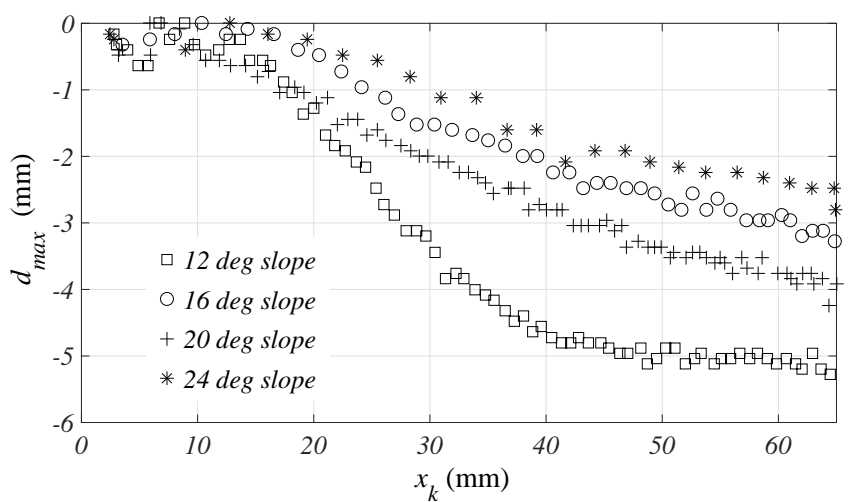

Figure 17: Variation in the maximum interface depth $d_{\max }$ with kink point $x_{k}$. For $\theta=12^{\circ}$ and $16^{\circ}$, the entrainable bed was located at $x_{\text {step }}=70 \mathrm{~cm}$, whereas for $\theta=20^{\circ}$ and $24^{\circ}$, the bed was located at $x_{\text {step }}=90 \mathrm{~cm}$.

the slope has less effect. At steeper slopes, this bulldozing motion was not seen; instead, the bed was strongly sheared and was only uplifted very close to the surge interface.

These differences due to slope were supported by the examination of the " $\mathrm{R}$ " experiments. Here, due to the differential seeding of the surge and the entrainable bed, the interface between the surge and the mobile bed as it deformed were clear to see. The curvature of this interface was much more pronounced at shallower slopes, showing a deeper surge intrusion into the bed that was consistent with a stronger slope-normal gravity component. In Fig. 17, the maximum depth of the interface $d_{\max }$ is plotted against the maximum downstream extent of the overriding surge $x_{k}$, showing this difference clearly. At shallower slopes the surge intruded more deeply, and the same happened when the entrainable bed was further downstream (thus reducing the velocity of the overriding flow).

As shown by Fig. 15, the front (point F) moved slower than the contact discontinuity (point $\mathrm{K}$ ), and F's motion has been interpreted as a wave propagating downward as a result of the impulse imparted by the incoming flow. To take a closer look at this behaviour, we computed the volume averaged velocity

$$
\langle u\rangle=\frac{1}{S} \int_{x_{\text {step }}}^{x_{\text {step }}+\ell_{\text {step }}} \int_{-\delta h}^{h} u(x, z, t) \mathrm{d} z \mathrm{~d} x,
$$


where $S$ is the surface of the observation window. We computed the volumeaveraged velocity from the time at which the surge entered the observation window until the moment when the surge (i.e. point $\mathrm{K}$ ) left this window. The procedure was repeated for eroding and non-eroding flows. Figure 18 shows that except for shallowest slopes $\left(12^{\circ}\right)$, entrainment caused a reduction in the mean velocity. This figure compares the combined run (in blue) in which both the bed and the flow were seeded, with the no-entrainment case (in red). At the beginning of entrainment, the surge entered the observation zone and came into contact with the entrainable bed. At this time, the mean velocity was very low, as the average is taken over the entire fluid shown, including the stationary material downstream. As the avalanche put this material into motion, the mean velocity rose, and nearly all the bed material was entrained by the end of the measurements. At steeper slopes, the internal streamwise velocity was clearly slower than the non-entraining case. This was likely due to momentum being imparted to the entrainable bed. At shallower slopes this was not the case: at $\theta=12^{\circ}$, the mean velocity due to entrainment exceeded that of the nonentraining case. This suggests that some slip occurred at the base, which seems possible given the velocity field in figure 16.

\section{Concluding remarks}

The present paper describes an experimental analysis of basal entrainment in shallow viscoplastic flows. Viscoplastic surges were created by releasing a fixed volume of a Herschel-Bulkley fluid onto a sloping bed. After travelling a certain distance from the reservoir, the surge encountered an erodible stationary layer made of the same fluid. The material and flume walls being transparent, we were able to study the internal velocity field inside the flow and the entrainable layer. The experimental results were compared with the predictions from lubrication theory. Within this theory, the momentum balance equations can be simplified by neglecting inertia terms and making use of the flow's shallowness [23-30]. An evolution equation (8) for the flow depth can then be inferred from the mass 
$\langle\hat{u}\rangle$

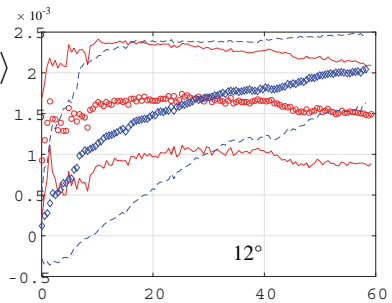

$\langle\hat{u}\rangle$

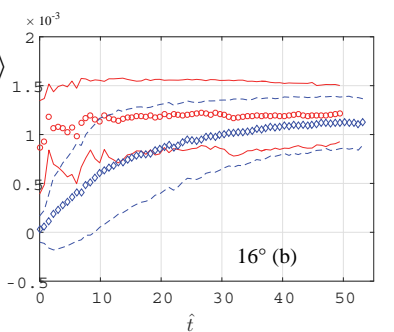

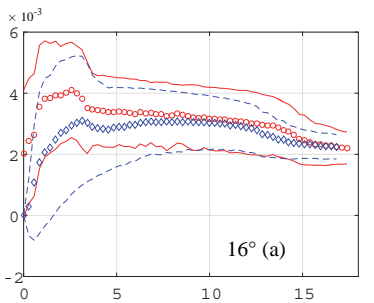

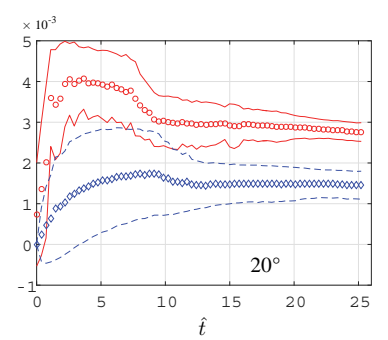

mean velocity, o entrainment

\pm 1 standard deviation

mean velocity,
with entrainment

\pm 1 standard deviation

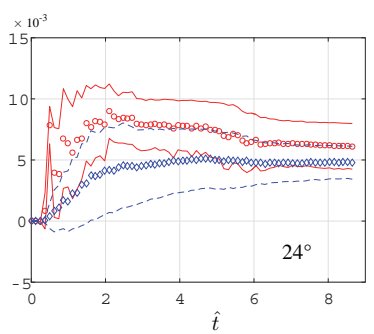

Figure 18: Variation in the dimensionless volume-averaged velocity $\langle u\rangle$ over time, for eroding (blue) and non-eroding (red) flows at slopes $\theta=12^{\circ}$ (run 12-6Ca), 16 ${ }^{\circ}$ (runs 16-6Ca and $16-6 \mathrm{Cb}$ ), $20^{\circ}$ (run 20-6Ca) and $24^{\circ}$ (run 24-6Ca). For $\theta=12^{\circ}$ and $16^{\circ}$ (a), the entrainable bed was located at $x_{\text {step }}=70 \mathrm{~cm}$, whereas for $\theta=16^{\circ}(\mathrm{b}), 20^{\circ}$ and $24^{\circ}$, the bed was located at $x_{\text {step }}=90 \mathrm{~cm}$ (see Table 1 ). To give an idea of the uncertainties associated with these measurements, we have plotted the confidence interval corresponding to $\pm \sigma$, with $\sigma^{2}$, the data variance. 
conservation equation.

Comparing theory with experiment was not straightforward, as lubrication theory overestimates front velocity at the earliest time periods, just after the surge release. This resulted in computed front positions about $25 \mathrm{~cm}$ ahead of the positions measured in our experiments. This problem was not new. In earlier publications, we reported that this might arise because of increased flowresistance due to flume sidewalls, the influence of inertia or the nontrivial evolution of the yield surface within the leading edge [61, 62]. To get around this problem, we used the following expedient: we compared the front position $x_{f}(t)$ of an entraining flow with the position $x_{f, 0}(t)$ that a non-entraining flow would reach at the same time $t$. In so doing, we found surprisingly good agreement between theory and experiment (see Fig. 11). A remarkable property of the diagram for $x_{f}\left(x_{f, 0}\right)$ is that it highlighted the irreversible increase in front position due to basal entrainment. This differed from the Newtonian case, for which basal entrainment caused front acceleration as long as the front was moving over the erodible stationary layer, but once the front reached the rigid base, it experienced such significant deceleration that all the influences of basal entrainment were quickly dissipated. For viscoplastic flows, basal entrainment caused front acceleration, but that gain was not lost when the front moved past the entrainable layer and onto the rigid bottom again. Another noticeable feature was the weak influence of flume inclination on front propagation over the entrainable layer: when the initial volume of fluid and the entrainable layer's depth were kept the same, altering the flume inclination did not cause any significant change in front position. This led us to think that mass was the key factor driving front motion.

If we leave aside the systematic difference between computed and measured front positions, lubrication theory can be considered to be a fairly good predictor of the effects of basal entrainment on the dynamics of shallow viscoplastic flows. However, observations from the present experiments told a different story about the mechanisms at work when a viscoplastic surge entrained an erodible layer. The surge was observed to sink into the entrainable bed, which forced 


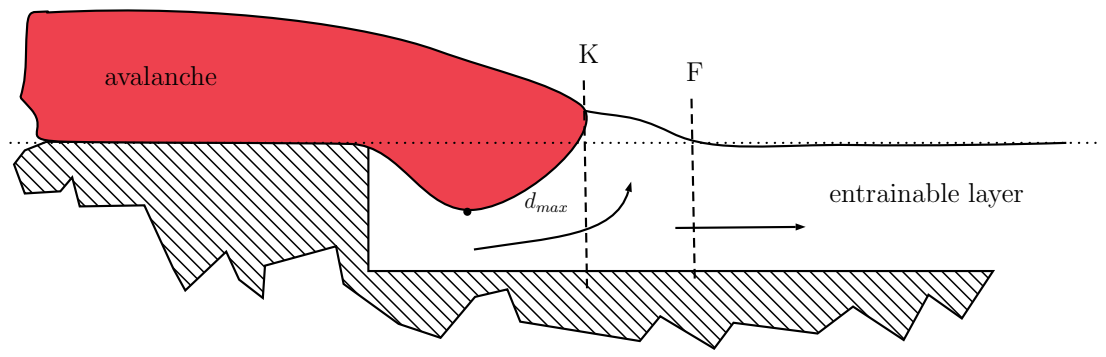

Figure 19: Diagram showing the bed deformation caused by the incoming surge. Point $K$ corresponds to the intersection between the contact discontinuity and the free surface: the furthest downstream point with fluid from the reservoir at that moment. Point $F$ corresponds to the flow front, i.e. the furthest point downstream with $h(x, t)>0$. The maximum excavation depth $d_{\max }$ is also shown.

downstream bed material to be uplifted into the flow front. The viscoplastic nature of the fluid meant that this happened locally. The former front of the original surge was still visible upstream in the form of an indentation or kink point (point K). The surge appeared to lose momentum to the bed, with a decrease in internal velocities compared to the non-entraining surge, except in the few cases where significant apparent basal slip occurred (see Fig. 18). Bed excavation was studied by examining the surge--bed interface, and it was found that the surge intruded into the bed much more deeply at shallower slopes. The diagram in Fig. 19 summarises how basal entrainment occurred. It differs significantly from the theoretical picture in Fig. 1. This diagram also explains why flume inclination had little influence on front motion: the surge scoured out the entrainable material, closely following the rigid geometry of the flume and leading to a concave surface over the cavity. The entrainable material was eventually pushed downstream as part of the flow front. This mass transfer was weakly affected by gravitational forces.

Other experimental observations were also insightful. First, we did not observe any formation of a static-flowing interface when the surge scoured the erodible stationary layer. If we looked at what was happening in the direction normal to the flume bottom, we noted that all the bed material in contact with 
the surge was quickly mobilised. In the streamwise direction, all the entrainable layer was slowly deformed over its entire length. Far ahead of the front, bed material velocities were low, but detectable using PIV. This suggests that the disturbance induced by the surge entering into contact with the erodible layer propagated quickly across that layer. Similarly to what was observed with Newtonian fluids [56], basal entrainment did not involve the propagation of a shock wave separating moving and stationary material, but rather involved an acceleration wave (if we adopt the terminology used in continuum mechanics [64]). Second, basal entrainment associated several processes (i.e. wave propagation, material uplift, buckling and possibly slip) and thus cannot be considered a unique local process. The situation differed significantly from the theoretically ideal model depicted in Fig. 1 (also see [18] for the Saint-Venant approach). Third, whereas the mechanisms observed were more complicated than initially believed, lubrication theory successfully captured the key features of eroding flows. This suggests that the errors balanced out. Our results substantiated the use of lubrication theory to model eroding viscoplastic flows. The assumption used here - the sudden incorporation of the entrainable layer into the flow-can also be applied to the Saint-Venant approach.

How the present results might be transposed to real processes is beyond the scope of this paper. Nevertheless, we would like to highlight that the basal entrainment scenario that emerges from our observations is consistent with the ploughing mechanism proposed by Gauer and Issler [65] for dense-snow avalanches. Whereas basal entrainment is difficult to monitor in real avalanches, field evidence shows that a wet-snow avalanche can "plough" the snow cover and push bed material ahead of the front. Figure 20 shows a small-scale example of an avalanche deposit (larger scale deposits are similar to this picture, but it is more difficult to capture the entire scene in a single picture). The snow tongue's front sank into the snow cover, pushing snow ahead of it. Snow compression led to a buckling instability, reproduced here by the numerous wrinkles on top of the snowpack surface and the lateral cracks. 


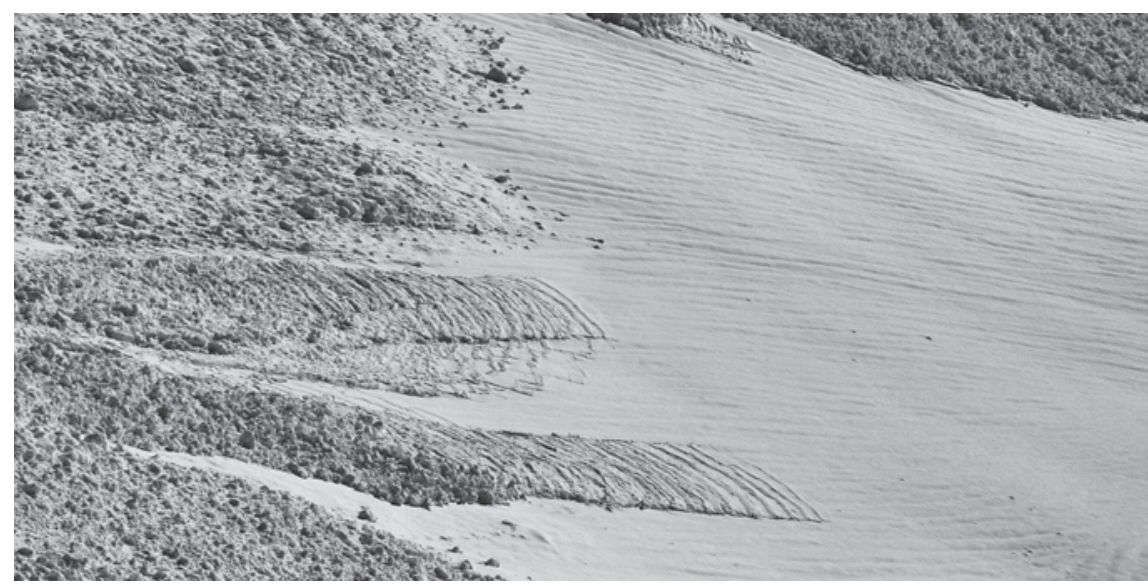

Figure 20: View of a wet-snow avalanche deposit. The avalanche mass eroded the snow cover before it came to a halt. The wrinkles seen on the snowpack cover suggest the occurrence of buckling, as in our experiments. The width of each snow tongue is approximately $50 \mathrm{~cm}$, and its thickness does not exceed $20 \mathrm{~cm}$.

\section{Acknowledgement}

The authors are grateful to Bob de Graffenried and Nicolas Andreini for valuable technical discussions. The work presented here was supported by the Swiss National Science Foundation under Grant No. 200021_146271/1 for a project called "Physics of Basal Entrainment." The authors are grateful to two anonymous reviewers for their feedback, their continuous support and astute comments that have considerably improved the original manuscript. The data used for plotting Figs. 9 to 12 are available from the figshare data repository: figshare.com/articles/Viscoplastic_surges/3497954. Three short video films are also included in this repository.

\section{Appendix A. Derivation of the extended evolution equation}

In this appendix, we derive the evolution equation (8).

In the shear-layer velocities will have the subscript $S$, and in the plug layer they will have the subscript $P$. Applying the no-slip boundary condition 
$u_{S}(x, z=b(x), t)=0$ on the rigid surface $b(x)$ and solving

$$
\left|\frac{\partial u}{\partial z}\right|=\left(\frac{1}{K}\left(\varrho g \sin \theta(h-z)\left(1-\cot \theta \frac{\partial h}{\partial x}\right)-\tau_{c}\right)\right)^{1 / n} .
$$

gives an equation for the velocity below the yield surface, in the shear layer:

$$
u_{S}(x, z, t)=\frac{n A}{n+1}\left(1-S \frac{\partial h}{\partial x}\right)^{1 / n}\left((Y(x, t)-b(x))^{1 / n}-(Y(x, t)-z)^{1+1 / n}\right) .
$$

In this arbitrary geometry the yield surface is now

$$
Y(x, t)=\max \left(h-\frac{\tau_{c}}{\varrho g\left|1-S \frac{\partial h}{\partial x}\right|}, b(x)\right) .
$$

Then, in the plug layer,

$$
u_{P}(x, t)=\frac{n}{n+1} A\left(1-S \frac{\partial h}{\partial x}\right)^{1 / n}\left((Y(x, t)-b(x))^{1+1 / n}\right) .
$$

The mass conservation equation is then used to obtain expressions for $\partial w_{S} / \partial z$ and $\partial w_{P} / \partial z$. These can be integrated using the no-slip condition $\boldsymbol{u}_{S} \cdot \boldsymbol{n}=0$ fixing the constant of integration below the yield surface, and the continuity of the velocity across the yield surface fixing the constant in the pseudo-plug region. Thus:

$$
\begin{aligned}
w_{S}(x, z, t) & =\frac{S \frac{\partial^{2} h}{\partial x^{2}}}{n+1}\left(1-S \frac{\partial h}{\partial x}\right)^{1 / n-1} A\left(\frac{n}{2 n+1}\left((Y-z)^{\frac{2 n+1}{n}}-(Y-b)^{2+1 / n}\right)\right. \\
& \left.+(Y-b)^{1+1 / n}(z-b)\right) \\
& -\left(1-S \frac{\partial h}{\partial x}\right)^{1 / n} A\left(\left(\frac{\partial Y}{\partial x}-\frac{\partial b}{\partial x}\right)(Y-b)^{1 / n}(z-b)\right. \\
& \left.+\frac{n \frac{\partial Y}{\partial x}}{n+1}\left((Y-z)^{1+1 / n}-(Y-b)^{1+1 / n}\right)\right), \\
w_{P}(x, z, t) & =\frac{S \frac{\partial^{2} h}{\partial x^{2}}}{n+1}\left(1-S \frac{\partial h}{\partial x}\right)^{1 / n-1} A\left((Y-b)^{1+1 / n}(z-b)-\frac{n(Y-b)^{2+1 / n}}{2 n+1}\right) \\
& -\left(1-S \frac{\partial h}{\partial x}\right)^{1 / n} A\left(\left(\frac{\partial Y}{\partial x}-\frac{\partial b}{\partial x}\right)(Y-b)^{1 / n}(z-b)\right. \\
& \left.-\frac{n \frac{\partial Y}{\partial x}(Y-b)^{1+1 / n}}{n+1}\right) .
\end{aligned}
$$


Finally, equations (A.2), (A.4) and (A.5) can be linked by solving for the kinematic boundary condition on the surface $z=h(x, t)$, so that

$$
\frac{\partial h}{\partial t}+u_{P} \frac{\partial h}{\partial x}=w_{P}
$$

giving

$\frac{\partial h}{\partial t}+A \frac{\partial}{\partial x}\left(\frac{n(Y-b)^{1+1 / n}}{(1+n)(1+2 n)}\left(1-S \frac{\partial h}{\partial x}\right)^{1 / n}(n(h-Y)+(n+1)(h-b))\right)=0$.

[1] C. Ancey, Snow Avalanches, in: S. L. Cutter (Ed.), Natural Hazard Science, Oxford University Press, Oxford, DOI:10. 1093/acrefore/9780199389407. 013. 17, 2016.

[2] S. S. Grigorian, M. E. Eglit, Y. L. Yakimov, A new formulation and solution of the problem of the motion of a snow avalanche (in Russian), Trudy Vycokogornogo Geofizichesko Instituta 12 (1967) 104-113.

[3] M. Eglit, Theoretical approaches to avalanche dynamics, Tech. Rep. Glaciological Data Report GD-16, World Data Center A for Glaciology, 1968.

[4] N. Bozhinskiy, K. S. Losev, The fundamentals of Avalanche Science, Tech. Rep. 55, SFL, Davos, 1998.

[5] K. Kelfoun, T. H. Druitt, Numerical modeling of the emplacement of Socompa rock avalanche, Chile, J. Geophys. Res. 110 (2005) B12202.

[6] R. M. Iverson, Debris-flow mechanics, in: M. Jakob, O. Hungr (Eds.), Debris-flow hazards and related phenomena, Springer, Berlin, 105-134, 2005.

[7] G. Parker, Y. Fukushima, H. M. Pantin, Self-accelerating turbidity currents, J. Fluid Mech. 171 (1986) 145-181.

[8] A. Elverhøi, D. Issler, F. V. De Blasio, T. Ilstad, C. B. Harbitz, P. Gauer, Emerging insights into the dynamics of submarine debris flows, Nat. Hazard Earth. Sys. Sci. 5 (2005) 633-648. 
[9] T. C. Pierson, K. M. Scott, Downstream dilution of a lahar: transition from debris flow to hyperconcentrated stream flow, Water Resour. Res. 21 (1985) 1511-1524.

[10] R. M. Iverson, The physics of debris flows, Rev. Geophys. 35 (1997) 245296.

[11] O. Hungr, S. G. Evans, Entrainment of debris in rock avalanches: An analysis of a long run-out mechanism, Geol. Soc. Amer. Bull. 116 (2004) $1240-1252$.

[12] O. Hungr, S. McDougall, M. J. Bovis, Entrainment of material by debris flows, in: M. Jakob, O. Hungr (Eds.), Debris-flow Hazard and Related Phenomena, Springer, Berlin, 135-158, 2005.

[13] S. A. Fagents, S. M. Baloga, Toward a model for the bulking and debulking of lahars, J. Geophys. Res. 111 (2006) B10201.

[14] B. Sovilla, P. Burlando, P. Bartelt, Field experiments and numerical modeling of mass entrainment in snow avalanches, J. Geophys. Res. 111 (2006) F03007.

[15] B. P. Kokelaar, R. L. Graham, J. M. N. T. Gray, J. W. Vallance, Finegrained linings of leveed channels facilitate runout of granular flows, Earth Planet. Sci. Lett. 385 (2014) 172-180.

[16] A. G. Kulikovskiy, E. I. Svehnikova, Model dlja rascheta dvizhija pilevoi snezhnoi lavini (a model for computing powdered snow avalanche motion) [in Russian], Materiali Glatsiologicheskih Issledovanii [Data of Glaciological Studies] 31 (1977) 74-80.

[17] C. Ancey, Powder-snow avalanches: approximation as non-Boussinesq clouds with a Richardson-number-dependent entrainment function, J. Geophys. Res. 109 (2004) F01005. 
[18] R. M. Iverson, C. Ouyang, Entrainment of bed material by Earth-surface mass flows: review and reformulation of depth-integrated theory, Rev. Geophys. 53 (2015) 27-58.

[19] J. M. Piau, Flow of a yield stress fluid in a long domain. Application to flow on an inclined plane, J. Rheol. 40 (1996) 711-723.

[20] P. Coussot, Mudflow Rheology and Dynamics, Balkema, Rotterdam, 1997.

[21] X. Huang, M. H. García, A Herschel-Bulkley model for mud flow down a slope, J. Fluid Mech. 374 (1998) 305-333.

[22] A. Siviglia, A. Cantelli, Effect of bottom curvature on mudflow dynamics: Theory and experiments, Water Resour. Res. 41 (2005) W11423.

[23] K. F. Liu, C. C. Mei, Slow spreading of a sheet of Bingham fluid on an inclined plane, J. Fluid Mech. 207 (1990) 505-529.

[24] C. C. Mei, M. Yuhi, Slow flow of a Bingham fluid in a shallow channel of finite width, J. Fluid Mech. 431 (2001) 135-159.

[25] G. P. Matson, A. J. Hogg, Two-dimensional dam break flows of HerschelBulkley fluids: the approach to the arrested state, J. Non-Newtonian Fluid Mech. 142 (2007) 79-94.

[26] N. J. Balmforth, R. V. Craster, P. Perona, A. C. Rust, R. Sassi, Viscoplastic dam breaks and the Bostwick consistometer, J. Non-Newtonian Fluid Mech. 142 (2007) 63-78.

[27] C. Ancey, S. Cochard, The dam-break problem for Herschel-Bulkley fluids down steep flumes, J. Non-Newtonian Fluid Mech. 158 (2009) 18-35.

[28] A. J. Hogg, G. P. Matson, Slumps of viscoplastic fluids on slopes, J. NonNewtonian Fluid Mech. 158 (2009) 101-112.

[29] P. Saramito, C. Smutek, B. Cordonnier, Numerical modeling of shallow non-Newtonian flows: Part I. The 1D horizontal dam break problem revis- 
ited, International Journal of Numerical Analysis \& Modeling, Series B 4 (2013) 283-298.

[30] L. Fusi, A. Farina, F. Rosso, Ill posedness of Bingham-type models for the downhill flow of a thin film on an inclined plane, Quarter. J. App. Math. 73 (2015) 615-627.

[31] R. B. Bird, G. C. Dai, B. J. Yarusso, The rheology and flow of viscoplastic materials, Rev. Chem. Eng. 1 (1983) 1-70.

[32] C. Ancey, Plasticity and geophysical flows: A review, J. Non-Newtonian Fluid Mech. 142 (2007) 4-35.

[33] N. J. Balmforth, I. A. Frigaard, G. Ovarlez, Yielding to Stress: Recent Developments in Viscoplastic Fluid Mechanics, Annu. Rev. Fluid Mech. 46 (2014) 121-146.

[34] P. Coussot, Yield stress fluid flows: A review of experimental data, J. NonNewtonian Fluid Mech. 211 (2014) 31-49.

[35] M. A. Kern, F. Tiefenbacher, J. N. McElwaine, The rheology of snow in large chute flows, Cold Reg. Sci. Technol. 39 (2004) 181-192.

[36] P. Coussot, D. Laigle, M. Arratano, A. Deganutti, L. Marchi, Direct determination of rheological characteristics of debris flow, J. Hydraul. Eng. 124 (1998) 865-868.

[37] M. Schatzmann, P. F. Fischer, G. R. Bezzola, Rheological behavior of fine and large particle suspensions, J. Hydraul. Eng. 129 (2003) 796-803.

[38] A. Remaître, J. P. Malet, O. Maquaire, C. Ancey, J. Locat, Flow behaviour and runout modelling of a complex debris flow in a clay-shale basin, Earth Surf. Process. Landforms (2005) 479-488.

[39] A. Castruccio, A. C. Rust, R. S. J. Sparks, Assessing lava flow evolution from post-eruption field data using Herschel-Bulkley rheology, J. Volcan. Geoth. Res. 275 (2014) 71-84. 
[40] R. M. Iverson, The debris-flow rheology myth, in: C. L. Chen, D. Rickenmann (Eds.), Debris flow Mechanics and Mitigation Conference, Mills Press, Davos, 303-314, 2003.

[41] J. M. N. T. Gray, Particle size segregation in granular avalanches: a brief review of recent progress, in: J. D. Goddard, J. T. Jenkins, P. Giovine (Eds.), 343-362, vol. 1227, AIP, Melville, NY, IUTAM-ISIMM Symposium on mathematical modeling and physical instances of granular flows, 343362,2010 .

[42] C. Ancey, Gravity Flow on Steep Slope, in: E. Chassignet, C. Cenedese, J. Verron (Eds.), Buoyancy Driven Flows, Cambridge University Press, New York, 372-432, 2012.

[43] S. D. R. Wilson, S. L. Burgess, The steady, spreading flow of a rivulet of mud, J. Non-Newtonian Fluid Mech. 79 (1998) 77-85.

[44] J. R. de Bruyn, P. Habdas, S. Kim, Fingering instability of a sheet of yield-stress fluid, Phys. Rev. E 66 (2002) 031504.

[45] I. A. Frigaard, D. P. Ryan, Flow of a visco-plastic fluid in a channel of slowly varying width, J. Non-Newtonian Fluid Mech. 123 (2004) 67-83.

[46] S. Cochard, C. Ancey, Experimental investigation into the spreading of viscoplastic fluids on inclined planes, J. Non-Newtonian Fluid Mech. 158 (2009) 73-84.

[47] G. Chambon, A. Ghemmour, M. Naaim, Experimental investigation of viscoplastic free-surface flows in a steady uniform regime, J. Fluid Mech. 754 (2014) 332-364.

[48] C. Ancey, Modélisation des avalanches denses, approches théorique et numérique, Houille Blanche 5-6 (1994) 25-39.

[49] D. Issler, Dynamically consistent entrainment laws for depth-averaged avalanche models, J. Fluid Mech. 759 (2014) 701-738. 
[50] M. E. Eglit, A. E. Yakubenko, Numerical modeling of slope flows entraining bottom material, Cold Reg. Sci. Technol. 108 (2014) 139-148.

[51] C. C. Mei, K. F. Liu, M. Yuhi, Mud flows - Slow and fast, in: N. J. Balmforth, A. Provenzale (Eds.), Geomorphological Fluid Mechanics: selected topics in geological and geomorphological fluid mechanics, Springer, Berlin, 548-577, 2001.

[52] H. Pascal, Propagation of disturbances in a non-Newtonian fluid, Physica D 39 (1989) 262-266.

[53] B. R. Duffy, D. Pritchard, S. K. Wilson, The shear-driven Rayleigh problem for generalised Newtonian fluids, J. Non-Newtonian Fluid Mech. 206 (2014) $11-17$.

[54] C. Ancey, B. M. Bates, Setting in motion and entraining a Herschel-Bulkley fluid, J. Non-Newtonian Fluid Mech. submitted.

[55] R. D. Skeel, M. Berzins, A method for the spatial discretization of parabolic equations in one space variable, SIAM J. Sci. Stat. Comput. 11 (1990) 1-32.

[56] B. M. Bates, N. Andreini, C. Ancey, Basal entrainment by Newtonian gravity-driven flows, Phys. Fluids 28 (2016) 053101.

[57] N. Andreini, Dam break of Newtonian fluids and granular suspensions: Internal dynamics measurements, Ph.D. thesis, Ecole Polytechnique Fédérale de Lausanne, 2012.

[58] M. Raffel, C. E. Willert, S. T. Wereley, J. Kompenhans, Particle Image Velocimetry, Springer, Berlin, 2007.

[59] J. K. Sveen, An introduction to MatPIV, Tech. Rep. eprint series No. 2 "Mechanics and Applied Mathematics" ISSN 0809-4403, Department of Mathematics, University of Oslo,, 2004. 
[60] B. M. Wilson, B. L. Smith, Uncertainty on PIV mean and fluctuating velocity due to bias and random errors, Meas. Sci. Technol. 24 (3) (2013) 035302 .

[61] N. Andreini, Epely-Chauvin, C. Ancey, Internal dynamics of Newtonian and viscoplastic fluid avalanches down a sloping bed, Phys. Fluids 24 (2012) 053101.

[62] C. Ancey, N. Andreini, Epely-Chauvin, Viscoplastic dam break waves: review of simple computational approaches and comparison with experiments, Adv. Water Resour. 48 (2012) 7991.

[63] C. Ancey, S. Cochard, The dam-break problem for Herschel-Bulkley viscoplastic fluids down steep flumes, J. Non-Newtonian Fluid Mech. 158 (1-3) (2009) 18-35.

[64] P. Chadwick, Continuum Mechanics: Precise Theory and Problems, Dover, Mineola, 1999.

[65] P. Gauer, D. Issler, Possible erosion mechanisms in snow avalanches, Ann. Glaciol. 38 (2003) 384-392. 
Table 2: Bulk experiments performed (Carbopol dyed with methylene blue).

\begin{tabular}{|c|c|c|c|c|c|c|}
\hline run name & slope, ${ }^{\circ}$ & $d, \mathrm{~mm}$ & $M, \mathrm{~kg}$ & $l_{\text {step }}, \mathrm{cm}$ & $l_{\text {bed }}, \mathrm{cm}$ & temp, ${ }^{\circ} \mathrm{C}$ \\
\hline $12-0 \mathrm{a}$ & 12 & - & 3 & 70 & - & 19.2 \\
\hline $12-6 \mathrm{Ra}$ & 12 & 6 & 3 & 70 & 30 & 19.2 \\
\hline $12-6 \mathrm{Ca}$ & 12 & 6 & 3 & 70 & 30 & 19.3 \\
\hline $16-0 c$ & 16 & 0 & 3 & 70 & - & 19.5 \\
\hline 16-3Rd & 16 & 3 & 3 & 70 & 30 & 19.9 \\
\hline $16-3 \mathrm{Cc}$ & 16 & 3 & 3 & 70 & 30 & 19.85 \\
\hline 16-3Re & 16 & 3 & 3 & 80 & 20 & 19.9 \\
\hline $16-3 \mathrm{Cd}$ & 16 & 3 & 3 & 80 & 20 & 19.9 \\
\hline $16-6 \mathrm{Rc}$ & 16 & 6 & 3 & 70 & 30 & 19.7 \\
\hline $16-6 \mathrm{Cc}$ & 16 & 6 & 3 & 70 & 30 & 19.5 \\
\hline 16-9Ra & 16 & 9 & 3 & 70 & 30 & 20 \\
\hline $16-9 \mathrm{Ca}$ & 16 & 9 & 3 & 70 & 30 & 20 \\
\hline 16-6Rd & 16 & 6 & 3 & 90 & 30 & 19.9 \\
\hline $16-6 \mathrm{Cd}$ & 16 & 6 & 3 & 90 & 30 & 19.65 \\
\hline $16-6 \mathrm{Cf}$ & 16 & 6 & 3 & 90 & 20 & 19.9 \\
\hline $16-6 \mathrm{Cg}$ & 16 & 6 & 3 & 90 & 15 & 19.5 \\
\hline 16-0e & 16 & 0 & 3 & 90 & - & 19.6 \\
\hline 20-0a & 20 & 0 & 3 & 90 & - & 19.45 \\
\hline $20-6 \mathrm{Ra}$ & 20 & 6 & 3 & 90 & 30 & 19.95 \\
\hline $20-6 \mathrm{Ca}$ & 20 & 6 & 3 & 90 & 30 & 20.1 \\
\hline $20-6 \mathrm{Rb}$ & 20 & 6 & 3 & 90 & 20 & 20 \\
\hline $20-6 \mathrm{Cb}$ & 20 & 6 & 3 & 90 & 20 & 19.8 \\
\hline $20-6 R c$ & 20 & 6 & 3 & 90 & 10 & 19.5 \\
\hline $20-6 \mathrm{Cc}$ & 20 & 6 & 3 & 90 & 10 & 19.65 \\
\hline $20-6 \mathrm{Cd}$ & 20 & 6 & 3 & 110 & 10 & 19.65 \\
\hline 20-6Rd & 20 & 6 & 3 & 110 & 10 & 19.9 \\
\hline $20-6 \mathrm{Ce}$ & 20 & 6 & 3 & 100 & 20 & 19.95 \\
\hline 20-6Re & 20 & 6 & 3 & 100 & 20 & 19.6 \\
\hline $20-3 \mathrm{Ra}$ & 20 & 3 & 3 & 90 & 30 & 19.55 \\
\hline $20-3 \mathrm{Ca}$ & 20 & 3 & 3 & 90 & 30 & 19.95 \\
\hline 24-0a & 24 & - & 3 & 90 & - & 19.45 \\
\hline 24-3Ra & 24 & 3 & 3 & 90 & 30 & 19.5 \\
\hline $24-3 \mathrm{Ca}$ & 24 & 3 & 3 & 90 & 30 & 19.4 \\
\hline 24-6Ra & 24 & 6 & 3 & 90 & 30 & 19.2 \\
\hline $24-6 \mathrm{Ca}$ & 24 & 6 & 3 & 90 & 30 & 19.2 \\
\hline
\end{tabular}

